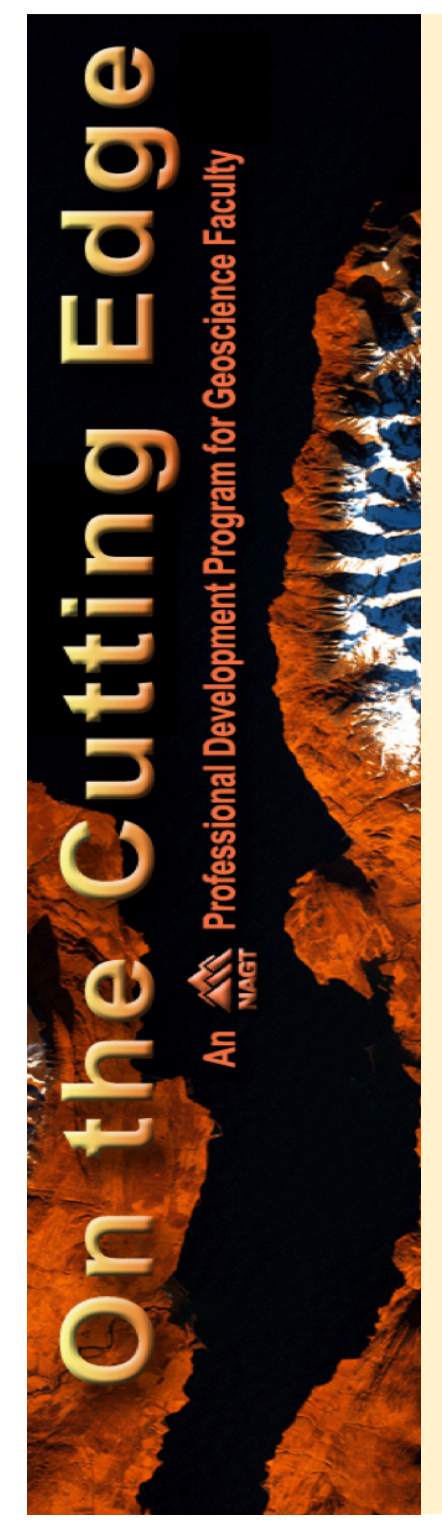

\title{
On The Cutting Edge Emerging Theme Workshops: A Pathway for Geoeducation Innovation
}

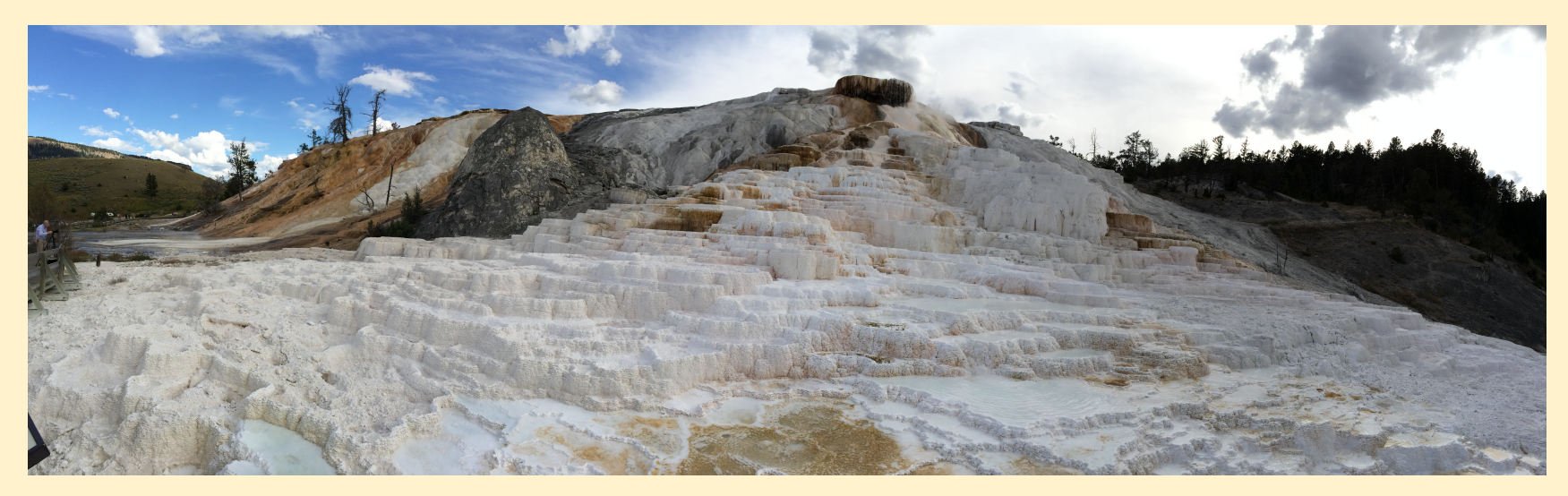

Michael E. Wysession, Washington University in St. Louis David W. Mogk, Montana State University Cathryn A. Manduca, Carleton College Heather Macdonald, College of William and Mary Barbara J. Tewksbury, Hamilton College 


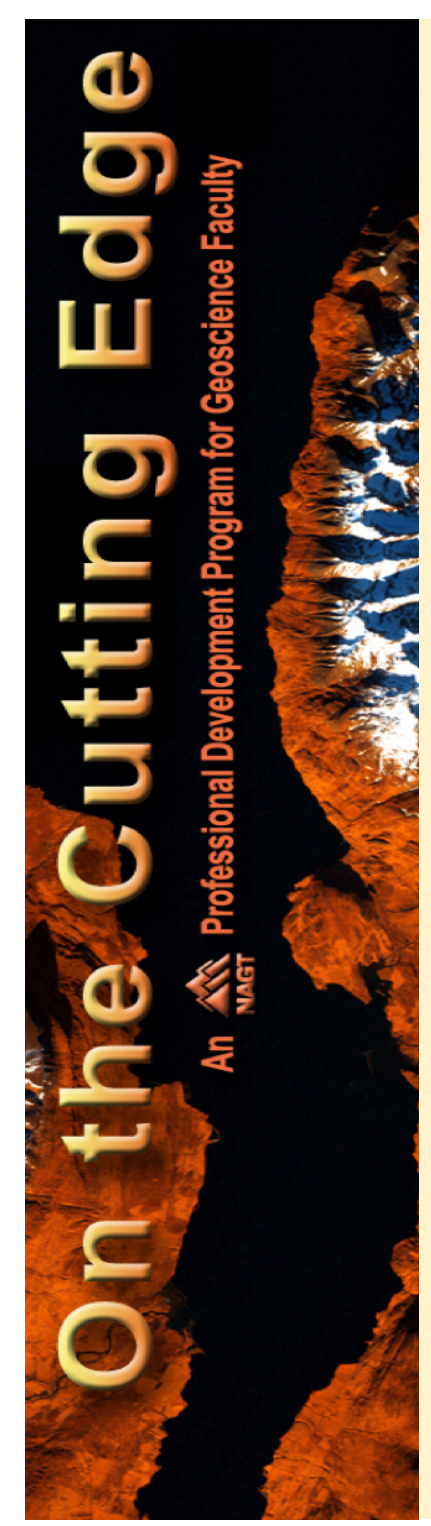

\section{OTCE Emerging Theme workshops were designed to catalyze rapid forward motion on high-priority topics for geoscience education}

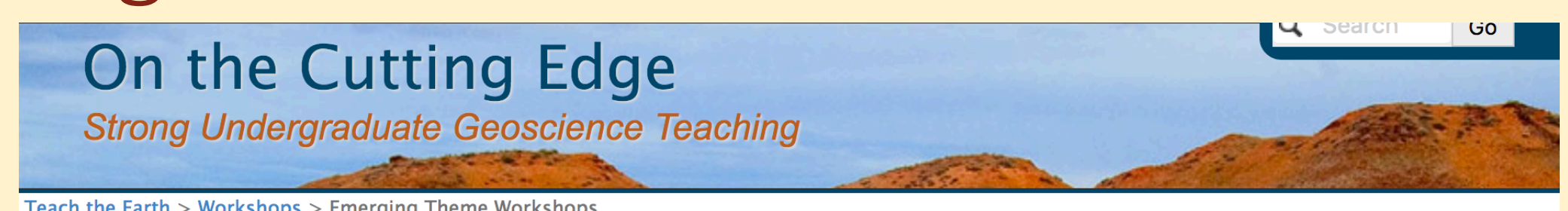

Teach the Earth $>$ Workshops $>$ Emerging Theme Workshops

Workshops

Workshop

Schedule

Workshop

Participant

Information

Emerging Theme

Workshops

Workshop

Stipends

Registration Fees

\section{Emerging Theme Workshops}

Workshop Goals I Developing an Action Plan I Resources

Geoscience education is in the midst of rapid change as research on learning provides new guidance for how we teach, as the revolution in understanding the Earth system changes what we teach, and as information technology provides new opportunities for teaching and research. Emerging theme workshops move important new topics from an initial stage of early activity by isolated leaders in the field toward widespread implementation in undergraduate geoscience courses. Topics are chosen where 1) it is clear that incorporation of the emerging topic into geoscience courses is important and will significantly enhance student understanding about the Earth and 2) a case can be made that a workshop will have a substantial impact in moving the content or pedagogy into broader use by geoscience faculty. Geoscientists and educators are invited to recommend topics. 


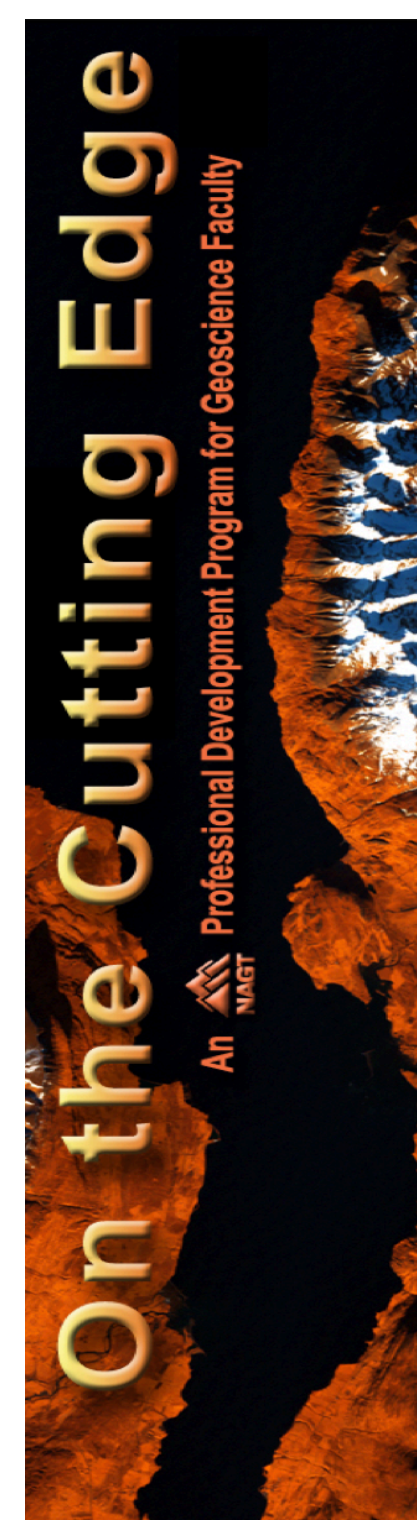

\section{Workshops addressed both} pedagogic and content opportunities spanning topics from teaching metacognition
The Role of Metacognition in Teaching

Geoscience

Carleton College, Northfield, Minnesota

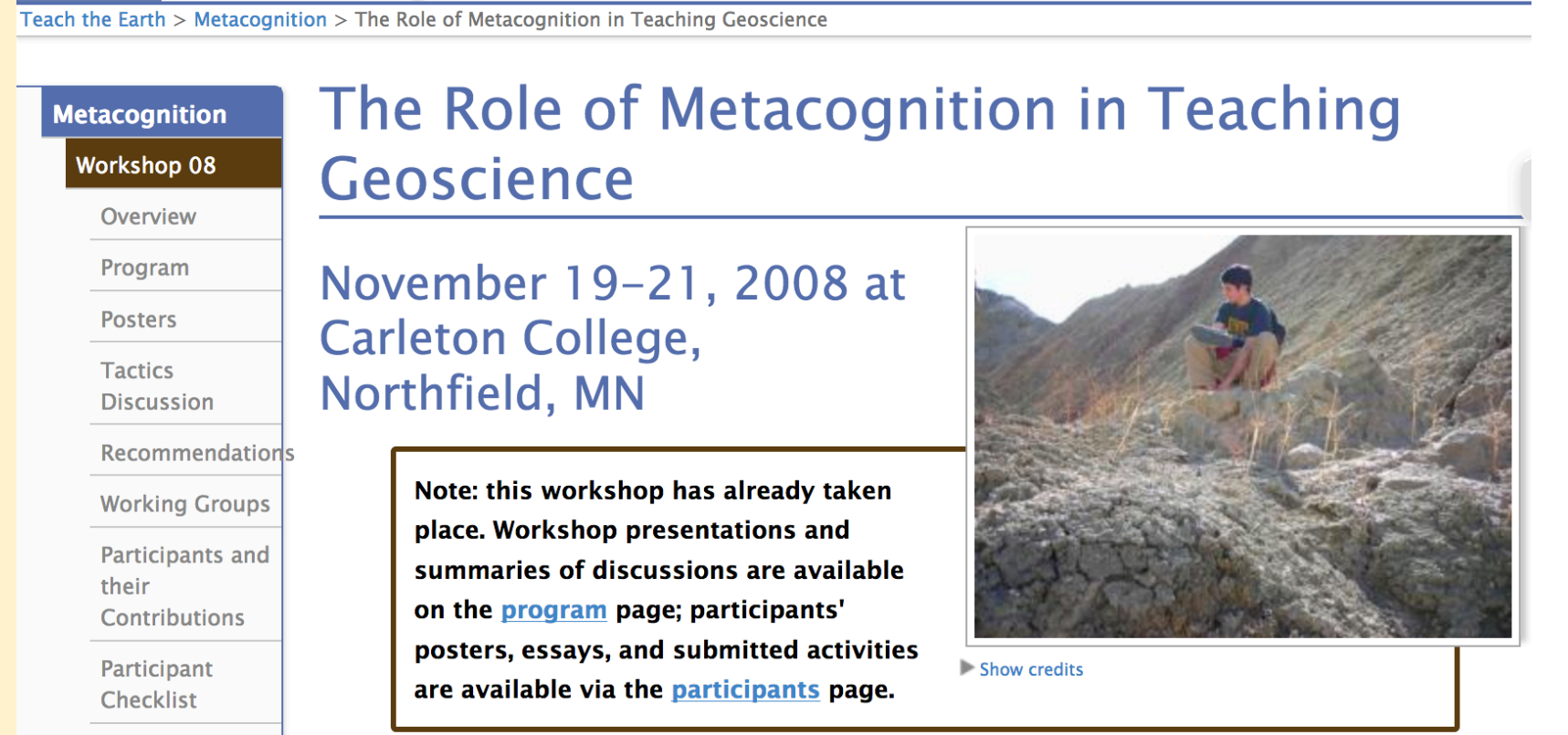

Logistics

Example Essays

Contribute a

Teaching

Activity
Metacognition, one's knowledge of one's own cognitive processes, is known to play a critical role in learning and the development of expertise (see, for example, How People Learn ). However, strategies for teaching metacognition are not yet widely developed or discussed in the geosciences. How do we help students become aware of their own thinking and learning to monitor their own learning strategies? What metacognitive skills are particularly important in developing geoscience expertise? How can these skills be effectively taught? 


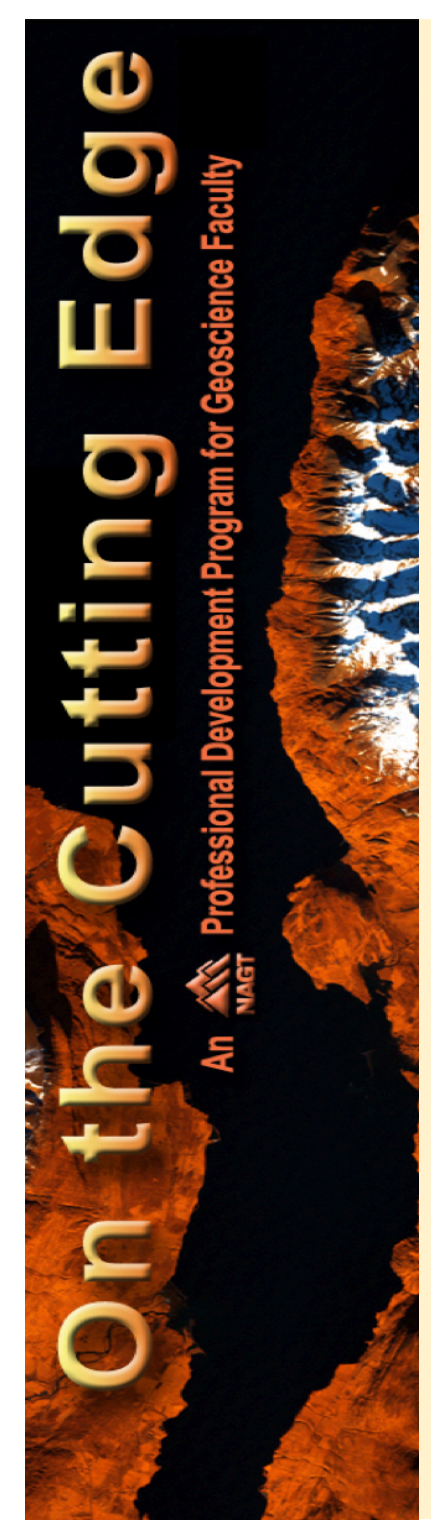

Workshops addressed both pedagogic and content opportunities spanning topics from teaching metacognition to Mars

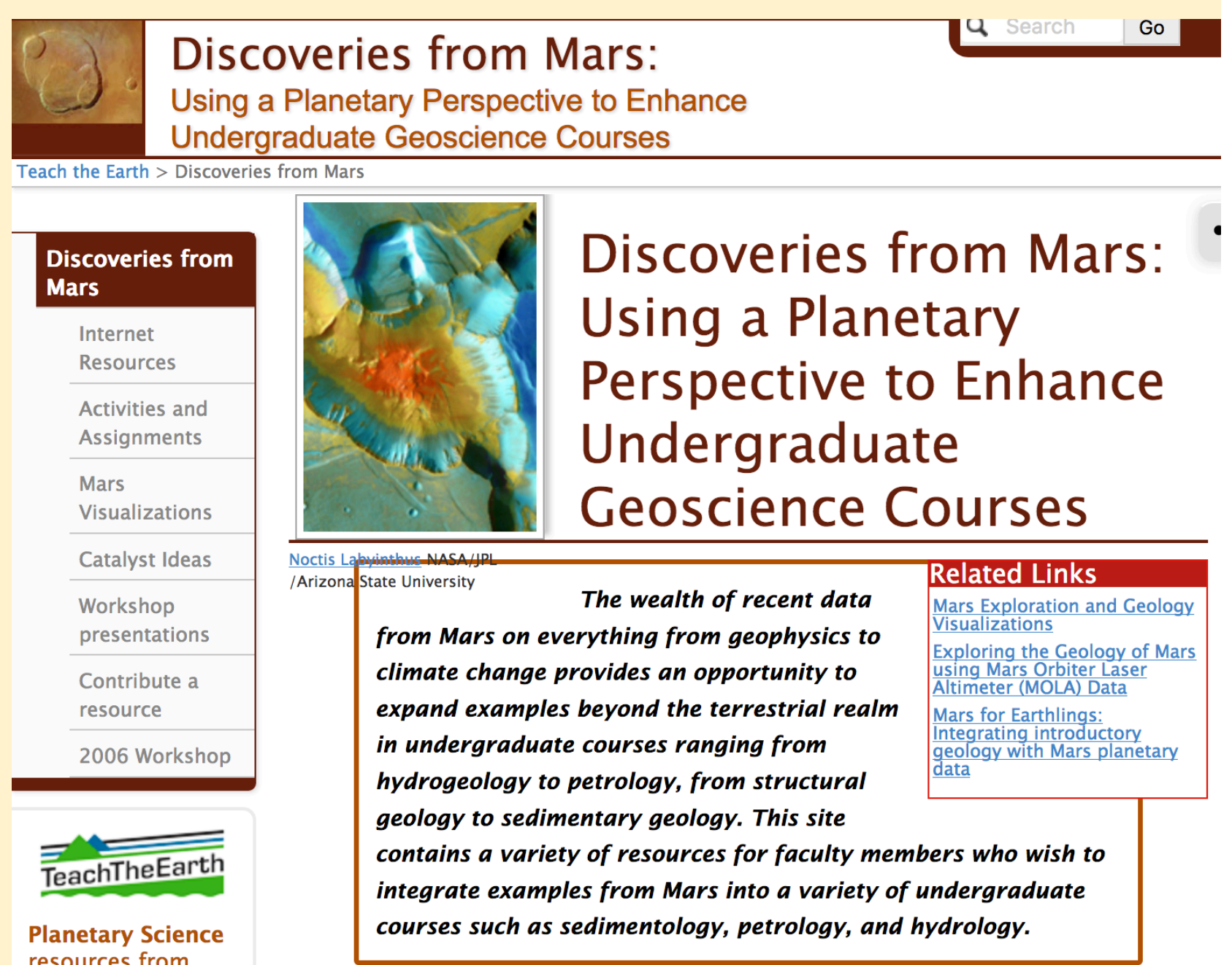




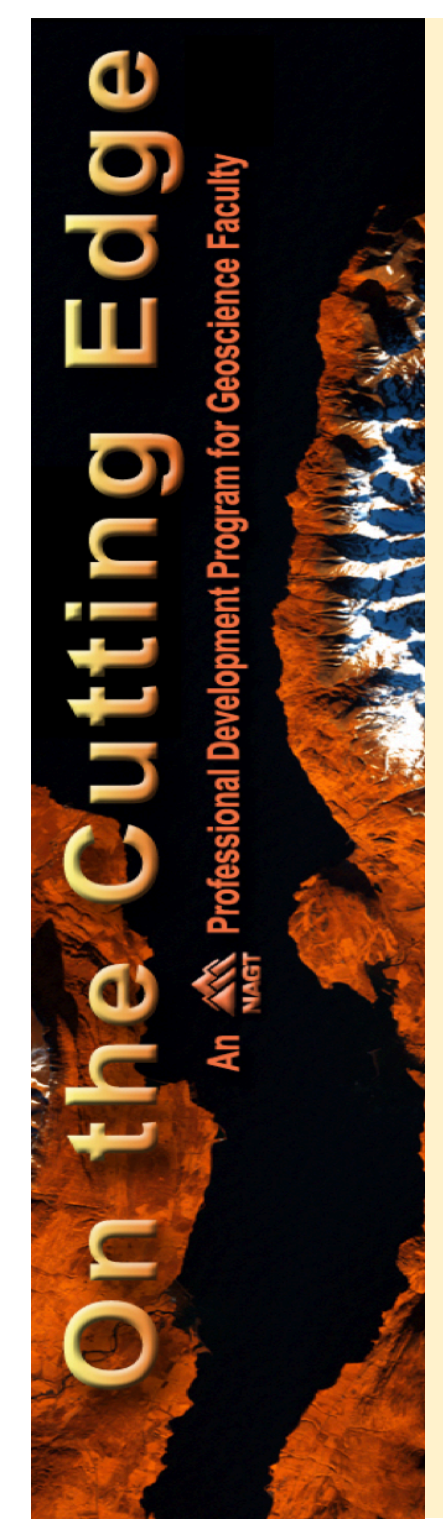

Workshops were both in person and online

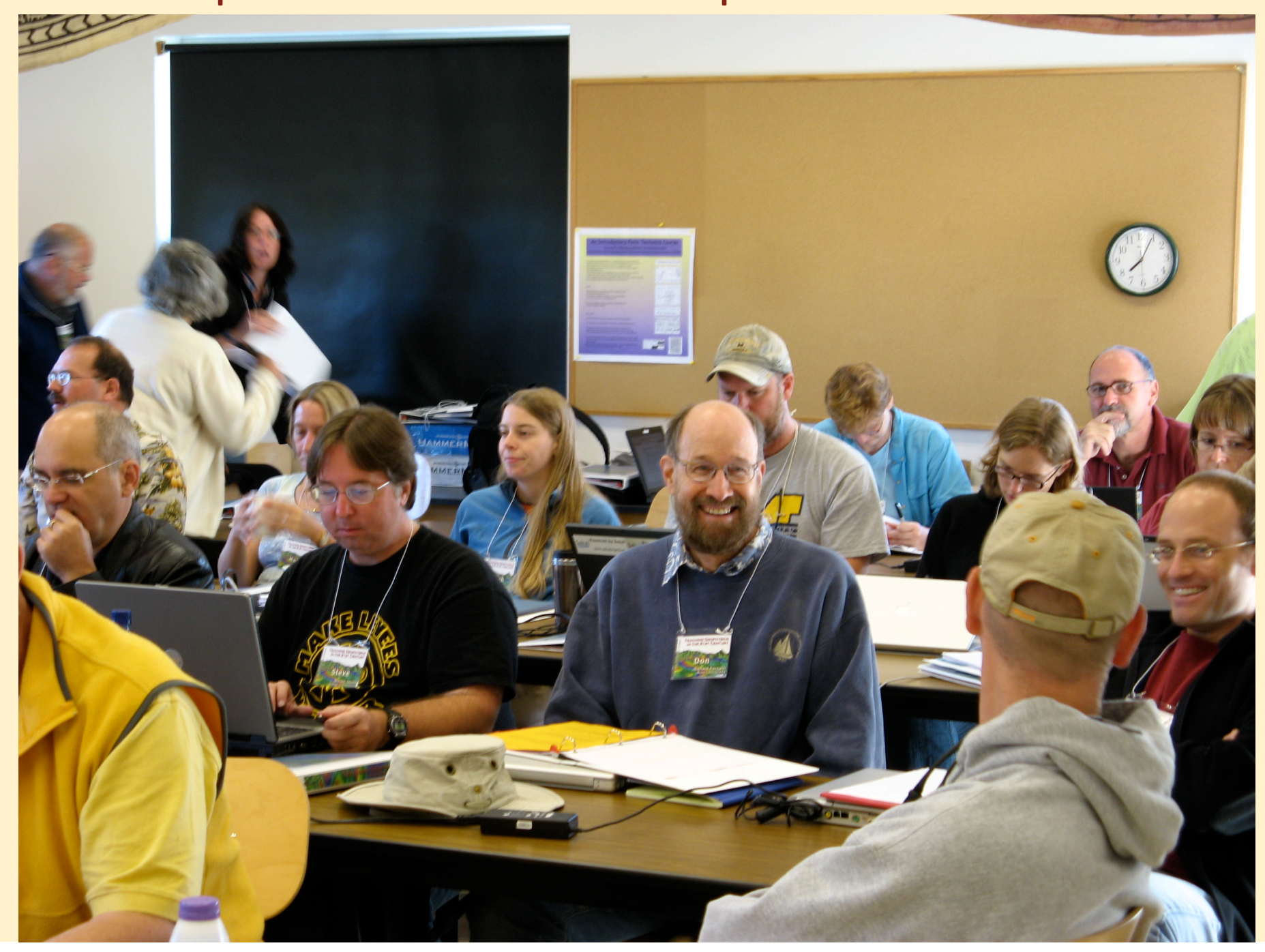




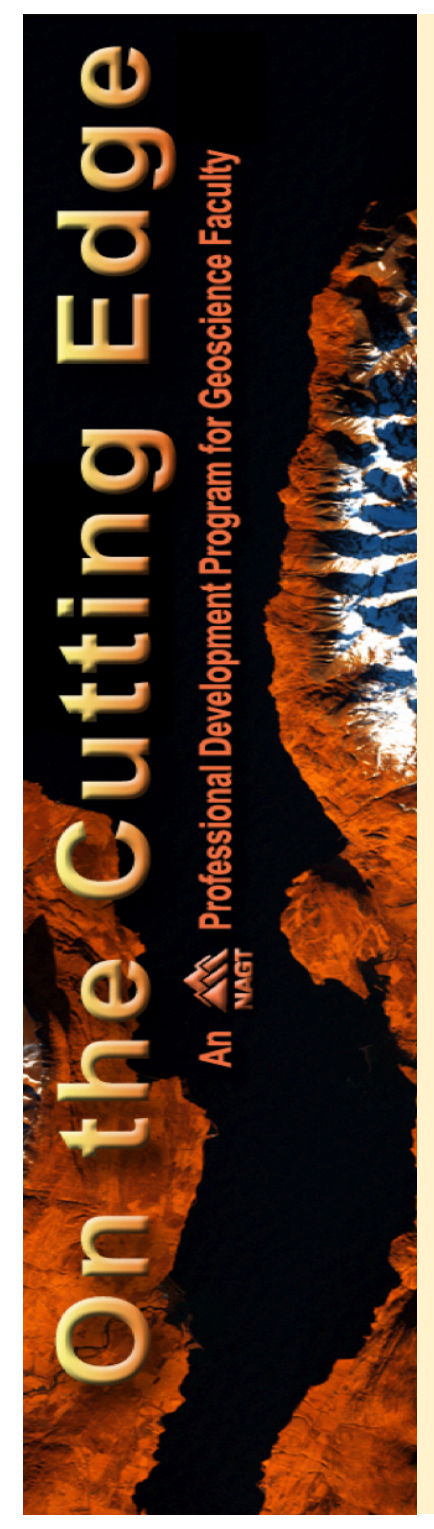

Emerging Theme Workshops moved fields toward widespread implementation within undergraduate geoscience courses.

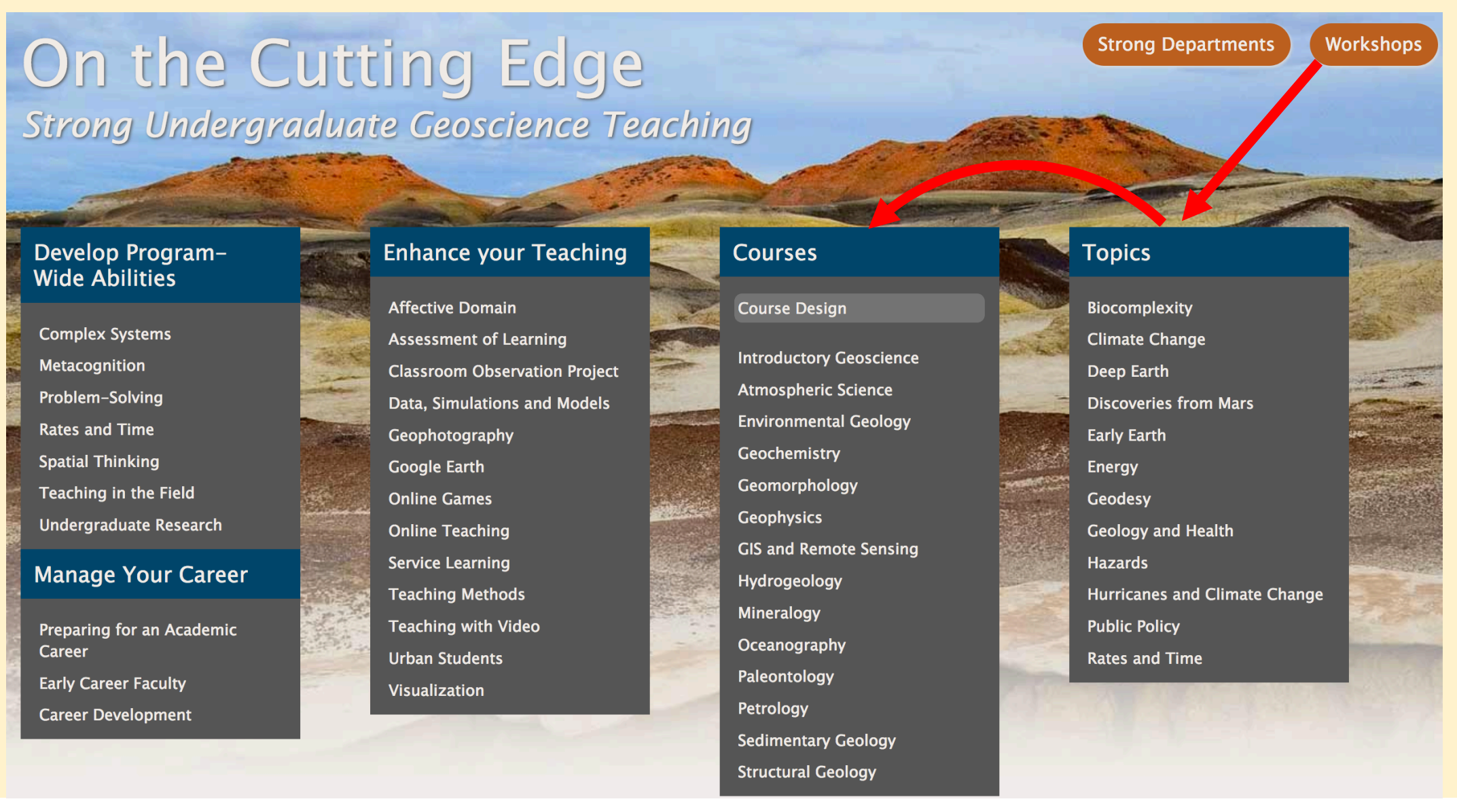




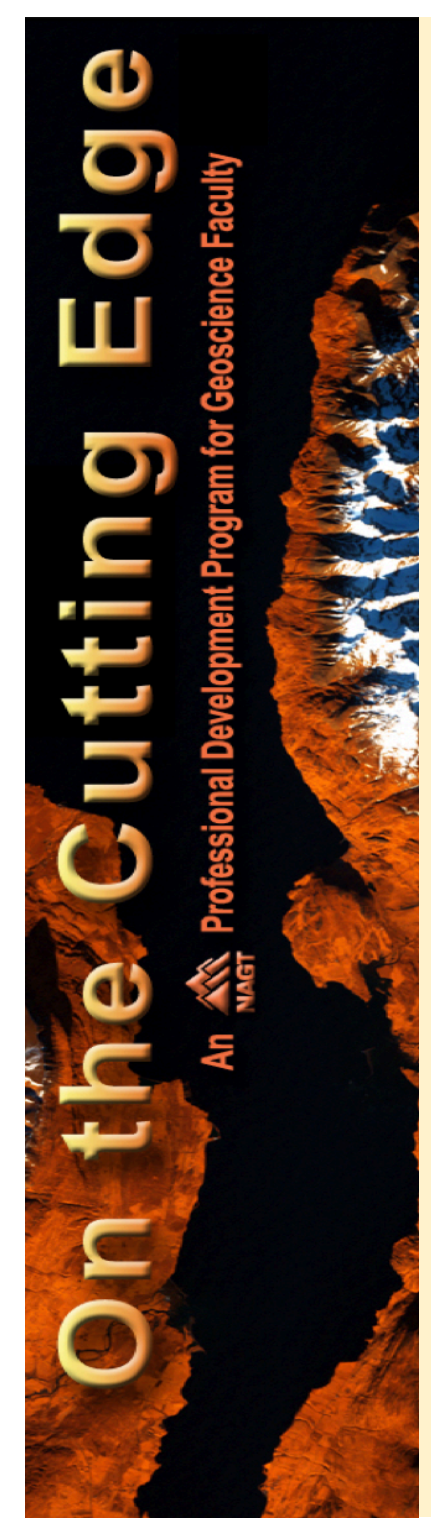

This synergy helped develop a leadership community, and workshops led to online collections that support wide dissemination

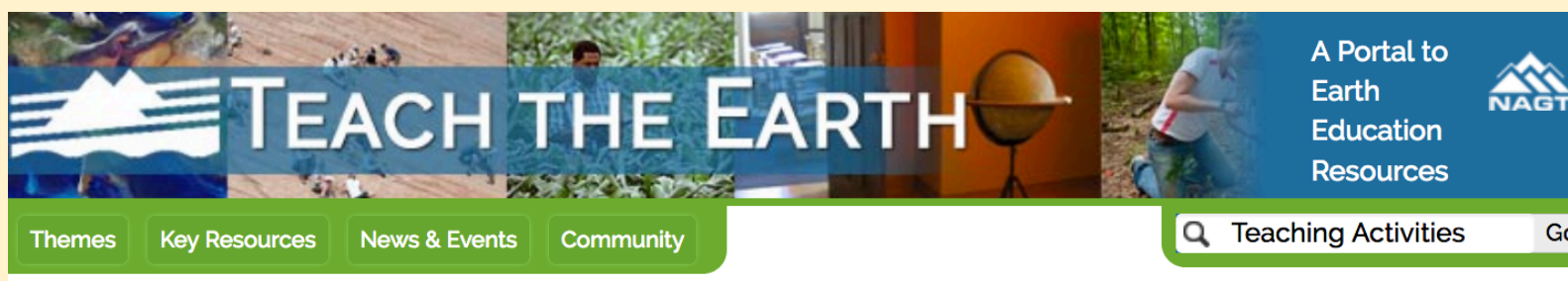

Teach the Earth

Search the Portal

Earth Education Project Sites

Community

News

Workshops,

Webinars and

Events

About this Portal

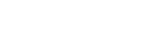

\section{Search the Portal}

This page allows you to search across all of the sites within the Teach the Earth portal.

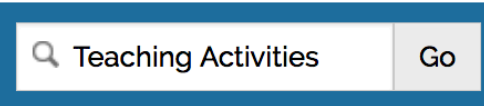

Help

Current Search Limits:

$x$ Text Search Teaching Activities

8 Subject Geoscience

Results $1-10$ of 3363 matches

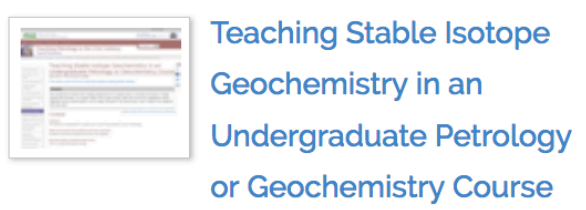

part of Petrology:Teaching Examples

This assignment includes three reading ascianments for students that (1)
Refine the Results $\downarrow$

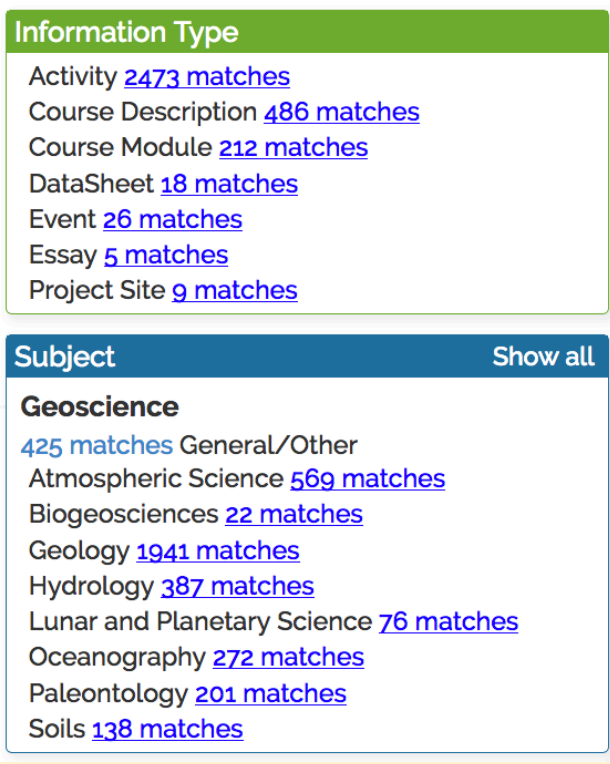



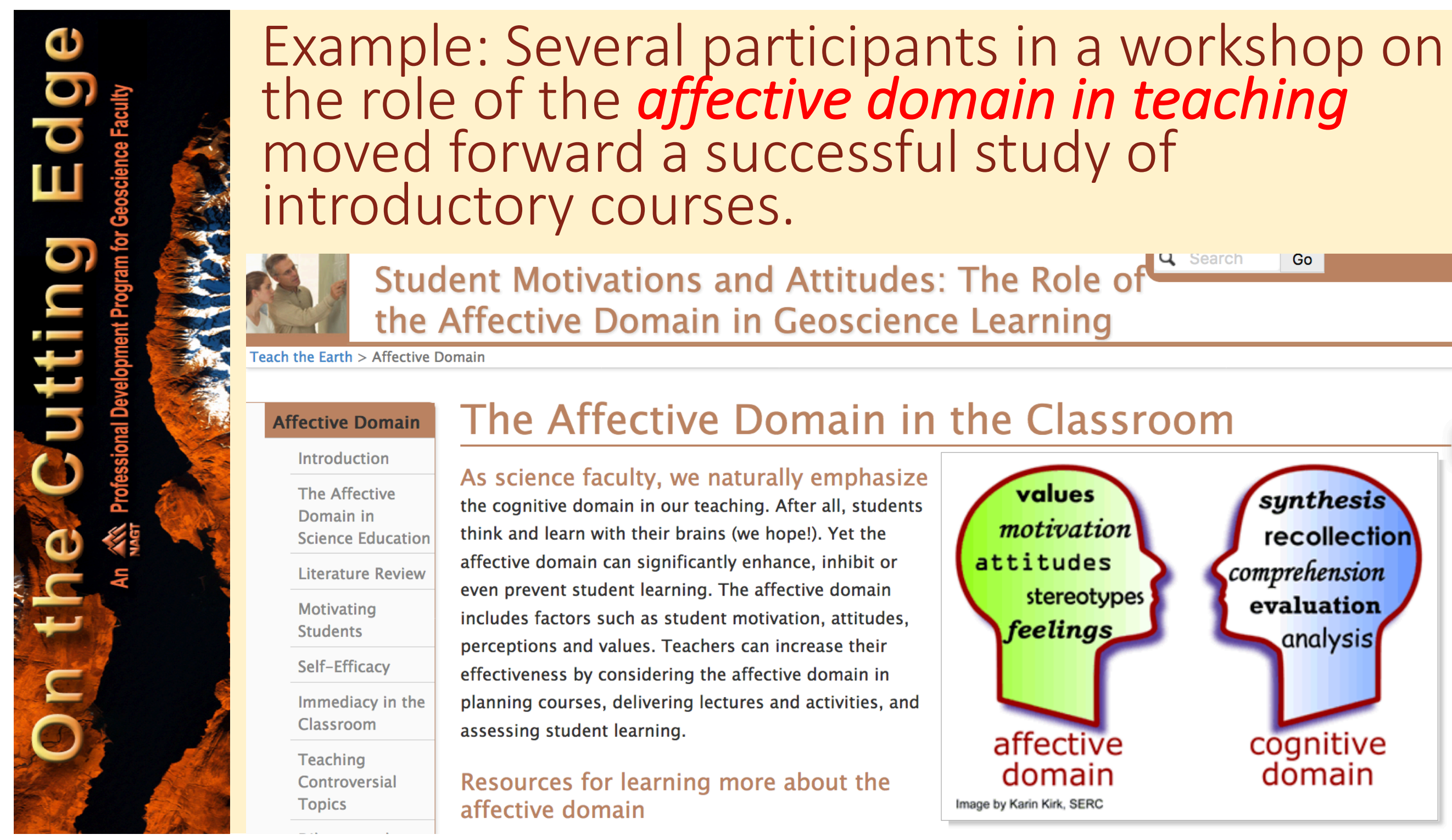
the role of the affective domain in teaching moved forward a successful study of introductory courses.

18. Student Motivations and Attitudes: The Role of 4 sarcon
the Affective Domain in Geoscience Learning

Teach the Earth > Affective Domain

Affective Domain

Introduction

The Affective

Domain in

Science Education

Literature Review

Motivating

Students

Self-Efficacy

Immediacy in the

Classroom

Teaching

Controversial

Topics

\section{The Affective Domain in the Classroom}

As science faculty, we naturally emphasize the cognitive domain in our teaching. After all, students think and learn with their brains (we hope!). Yet the affective domain can significantly enhance, inhibit or even prevent student learning. The affective domain includes factors such as student motivation, attitudes, perceptions and values. Teachers can increase their effectiveness by considering the affective domain in planning courses, delivering lectures and activities, and assessing student learning.

Resources for learning more about the affective domain

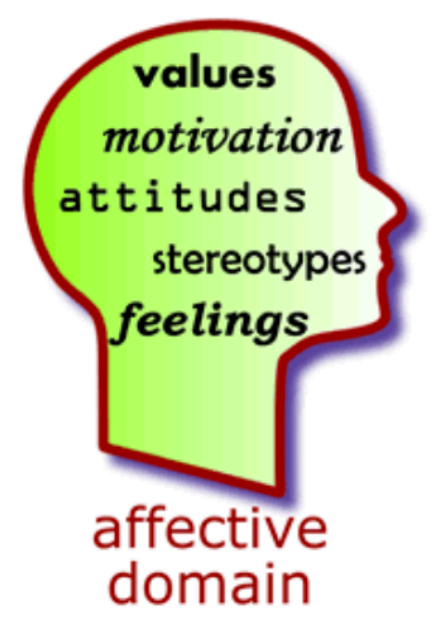

Image by Karin Kirk, SERC

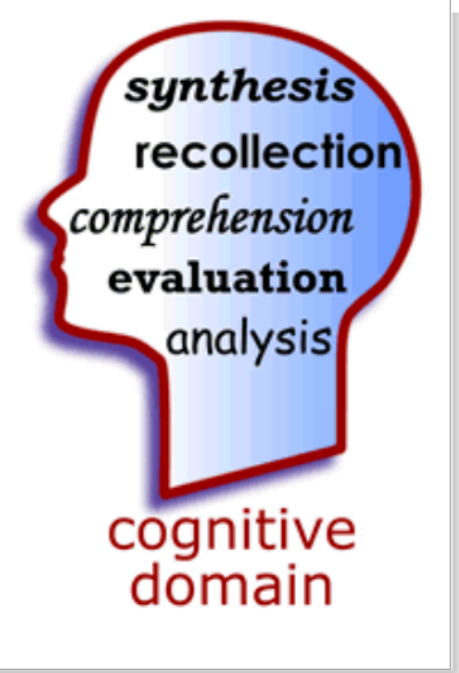




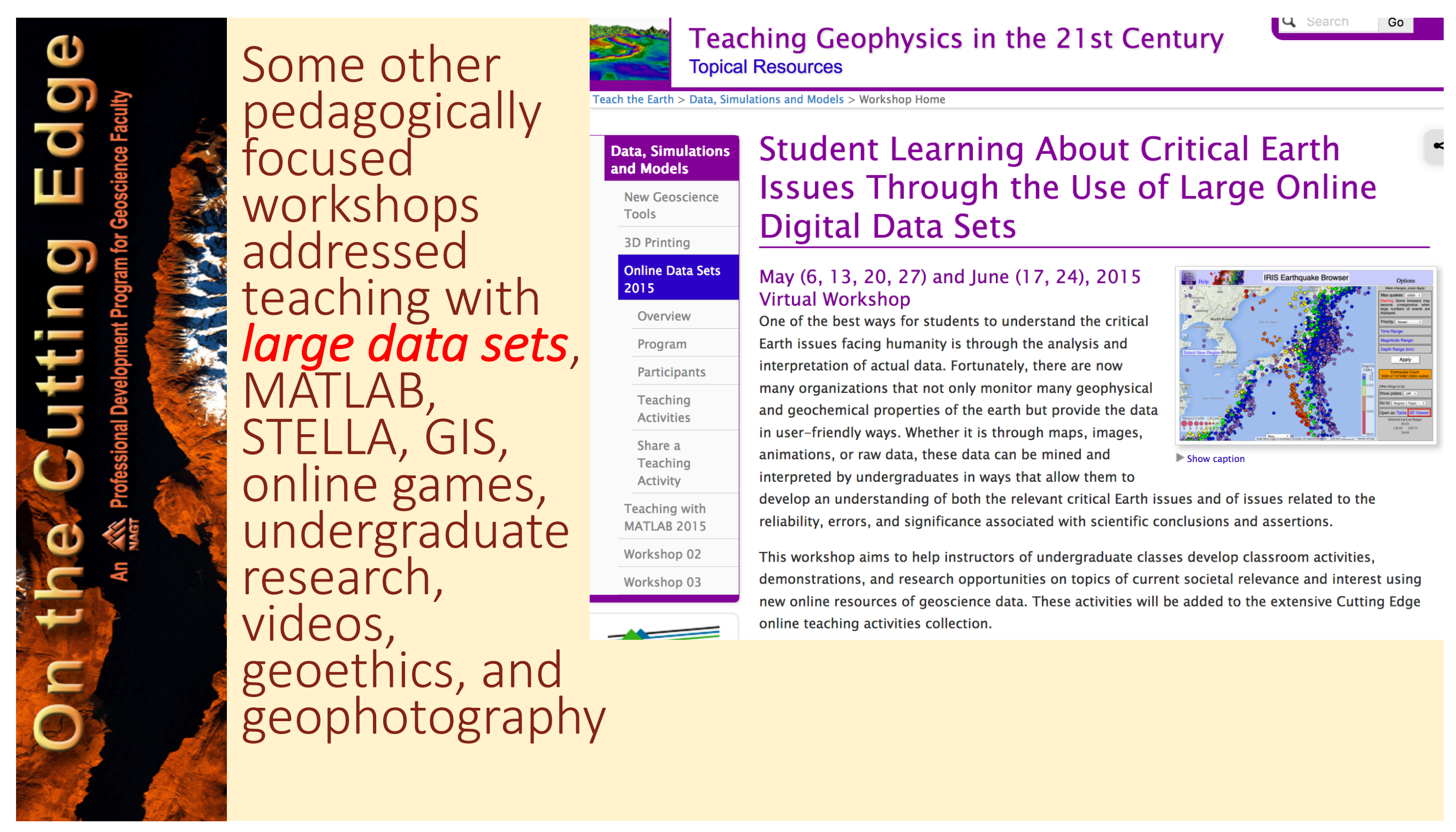




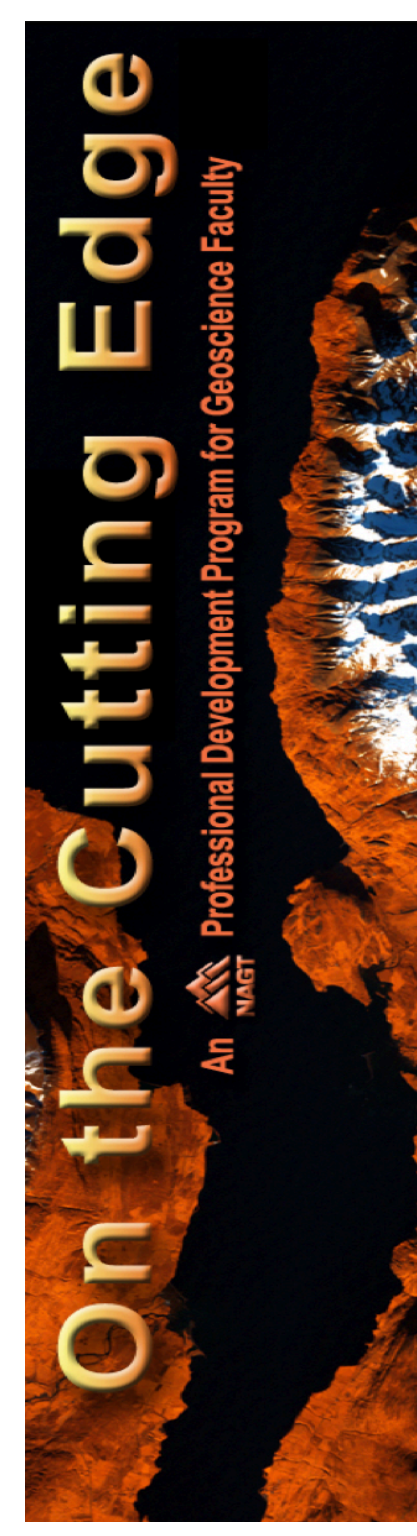

Some other pedagogically focused workshops addressed teaching with large data sets, MATLAB, STELLA, GIS, online games, undergraduate research, videos, geoethics, and geophotography

Workshop: Carleton College- Northfield, MN

Teach the Earth > Data, Simulations and Models $>$ Teaching with MATLAB

Data, Simulations and Models

New Geoscience

Tools

3D Printing

Online Data Sets

2015

Teaching with

MATLAB 2015

Workshop

Synthesis

Workshop

Outcomes

Overview

Program

Workshop

Participants

Teaching

Activities

Essays

Courses
Teaching Geoscience with MATLAB ${ }^{\oplus}$ Workshop

October 18-20, 2015

Carleton College, Northfield, MN

Note: this workshop has already taken place. Read the workshop synthesi for a summary of key ideas and see the workshop outcomes for materials developed in association with the workshop. Workshop presentations and

Related Links Computation in the Sciences
Using MATLAB summaries of discussions are available on the program page; participants' essays and program descriptions are available via the participants page. [br]

This workshop is designed to explore how teaching with MATLAB can enhance the student learning environment in undergraduate Earth Science and related courses. MATLAB can be applied to solving problems and developing systems involving mathematical computation, data analytics and statistics, signal and image processing, geographica mapping, and more in the scientific and engineering domains. As a participant, you will help build a collection of teaching activities that showcase how you utilize MATLAB in

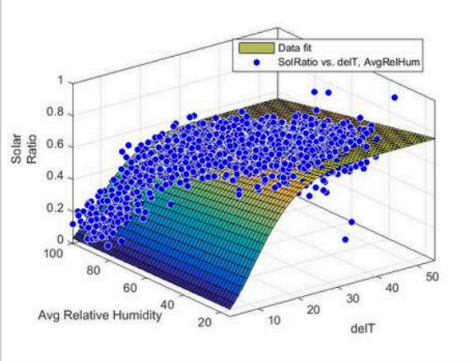
your classroom. 


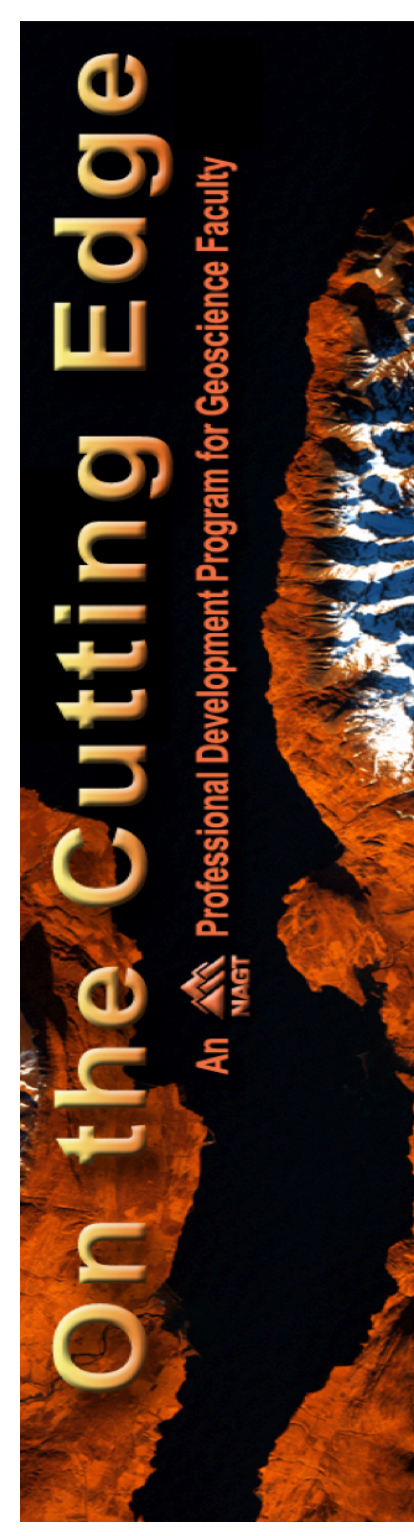

Some other pedagogically focused workshops addressed teaching with large data sets, MATLAB, STELLA, GIS, online games, undergraduate research, videos, geoethics, and geophotography

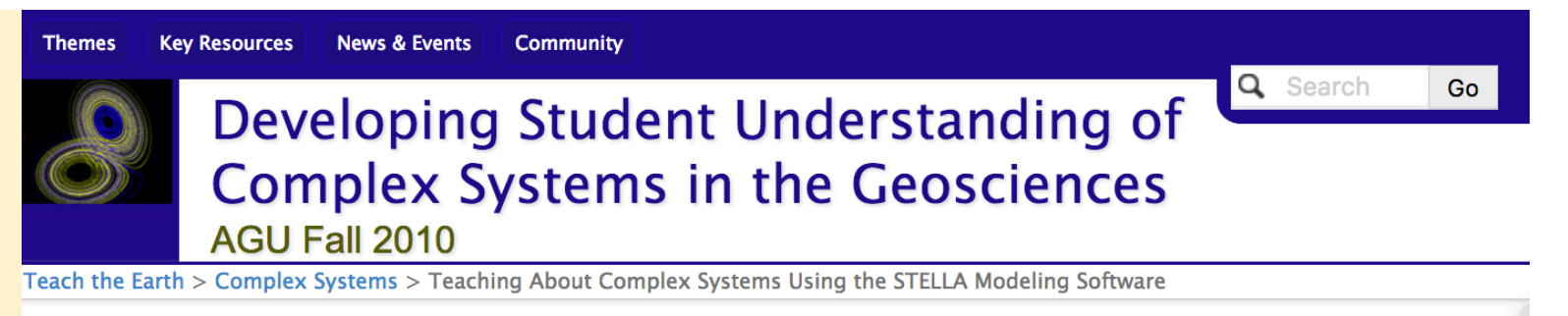

\section{Complex Systems \\ AGU Modeling \\ Workshop 2010 \\ Teaching About Complex Systems Using the STELLA Modeling Software}

Overview

Program

Participants

Pre-Workshop

Assignment

Modeling

Exercise Ideas

Workshop 2010

TeachTheEarth

Complex Systems resources from

across Teach the Earth »

Sunday, December 12, 2010, 9:00 am - 5:30 $\mathrm{pm}$

In conjunction with the AGU

Annual Meeting in San Francisco, CA

City College of San Francisco Ocean Campus

Fee: US $\$ 50$ | Limit: 25 participants | Registration deadline: November 22, 2010

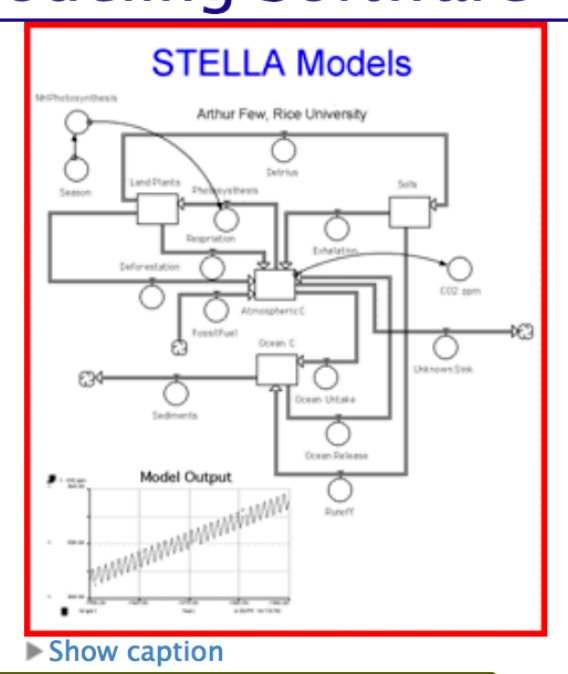

Note: This workshop has already taken place. See the workshop program for links to presentations and other material from the workshop. 


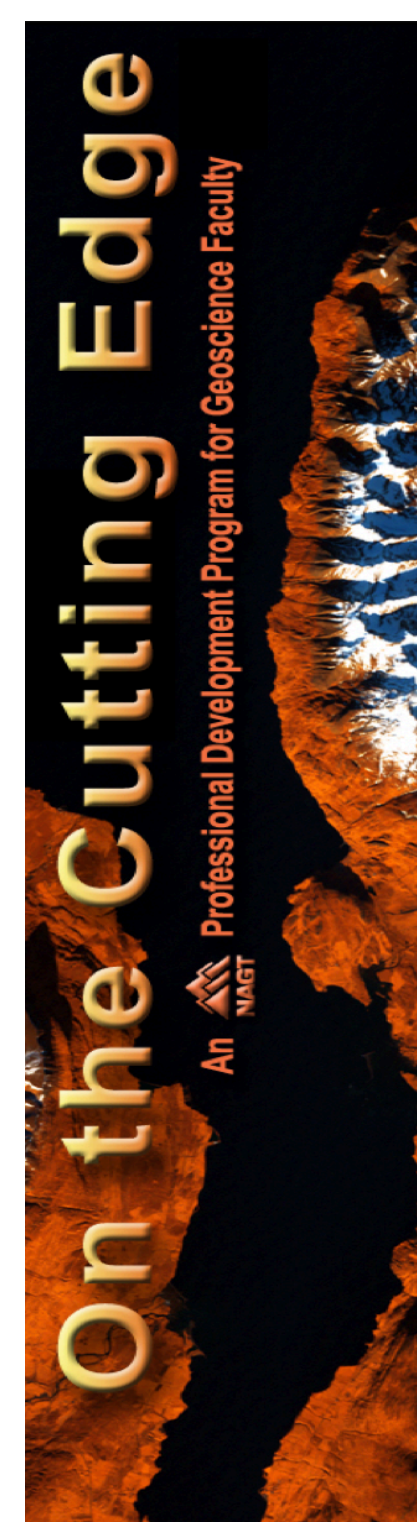

Some other pedagogically focused workshops addressed teaching with large data sets, MATLAB, STELLA, GIS, online games, undergraduate research, videos, geoethics, and geophotography

Course Design

Course Design Tutorial

...click to see 6

more

Workshop 2010

Workshop 2011

Overview

Program

Participants

Participant

Workspace

Schedule

summary

Assignments

Discussion

board

Submit resource

Workshop 2012

= TeachTheEarth

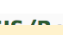

Designing GIS and Remote Sensing Courses, Modules, and Activities for Teaching Geoscience Students

An online workshop with opportunities for face-to-face interaction

Beginning March 2011 and ending October 2011.

Registration is closed for this workshop.

Finding the time, energy, and inspiration to develop new GIS or Remote Sensing course and activities, or to re-design an existing one, can be a challenge for faculty. Furthermore, many CIS and remote sensing courses are taught in departments other than geology departments and incorporate few geological examples, and many geology majors graduate with little experience using CIS and remote sensing to solve geology-related problems.

This workshop is designed for 1) geology faculty who want to develop GIS and remote sensing

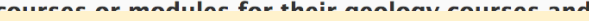

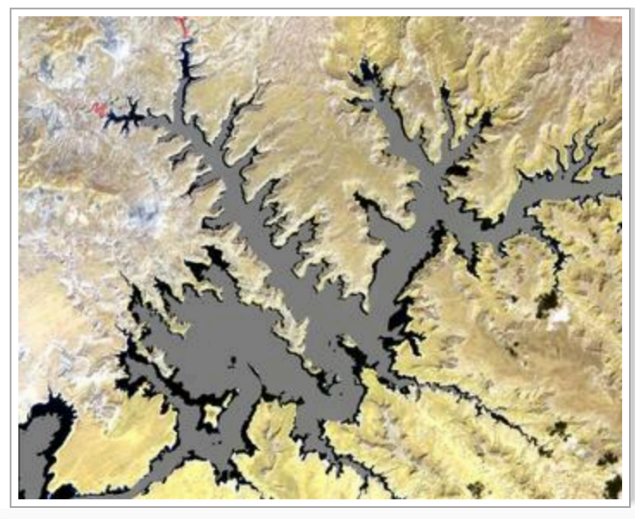




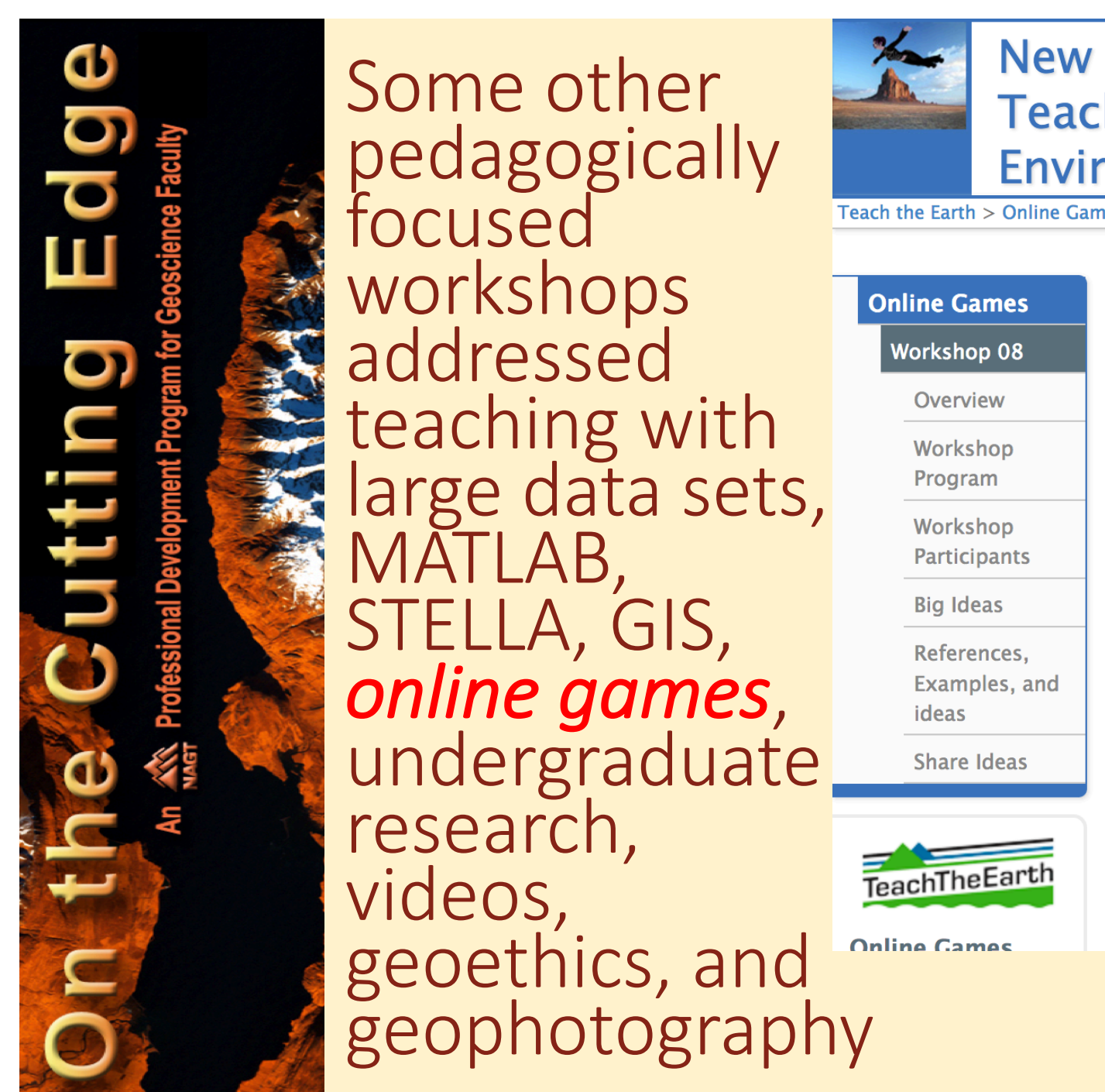




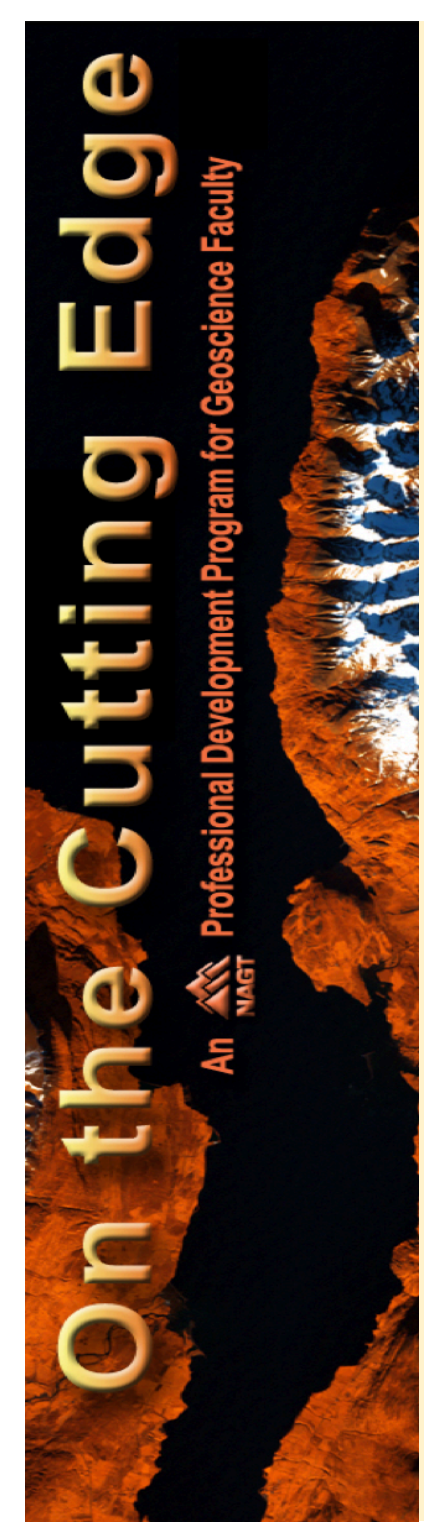

Some other pedagogically focused workshops addressed teaching with large data sets, MATLAB, STELLA, GIS, online games, undergraduate research, videos, geoethics, and geophotography
Undergraduate Research as Teaching Practice

Montana State University- Bozeman, MT
Undergraduate Research

2014 Workshop

Overview

Participants

Activities

Program

Participant

Workspace

Stream Table

Modeling

2015 AGU

Workshop

\section{TeachTheEarth}

Undergrad

Research

resources from

across Teach the

Earth »

\section{Undergraduate Research in Earth} Science Classes: Engaging Students in the First Two Years

\section{August 10-13, 2014}

Related Links

Montana State University, Bozeman MT

This workshop has already taken place. For more information about what happened at the workshop, please see presentations and other materials linked from the Workshop Program.

This workshop is designed to explore the many ways that authentic research experiences can be embedded in introductory Earth Science courses. This follows the recent recommendations from the President's Council of Advisors on Science, Technology, Engineering and Mathematics (PCAST, 2012 (Acrobat (PDF) 5.3MB Feb8 17)): Advocate and provide support for replacing standard laboratory courses with discovery-based research courses. Access to Earth data, information technology, instrumentation, field experiences and new understanding of how students learn (e.g., through Discipline-Based Education Research, NRC 2012) provide unprecedented opportunities for students to engage authentic research at early stages in their careers. Early exposure to research experiences has shown to be effective in the recruitment of students, improved retention and 


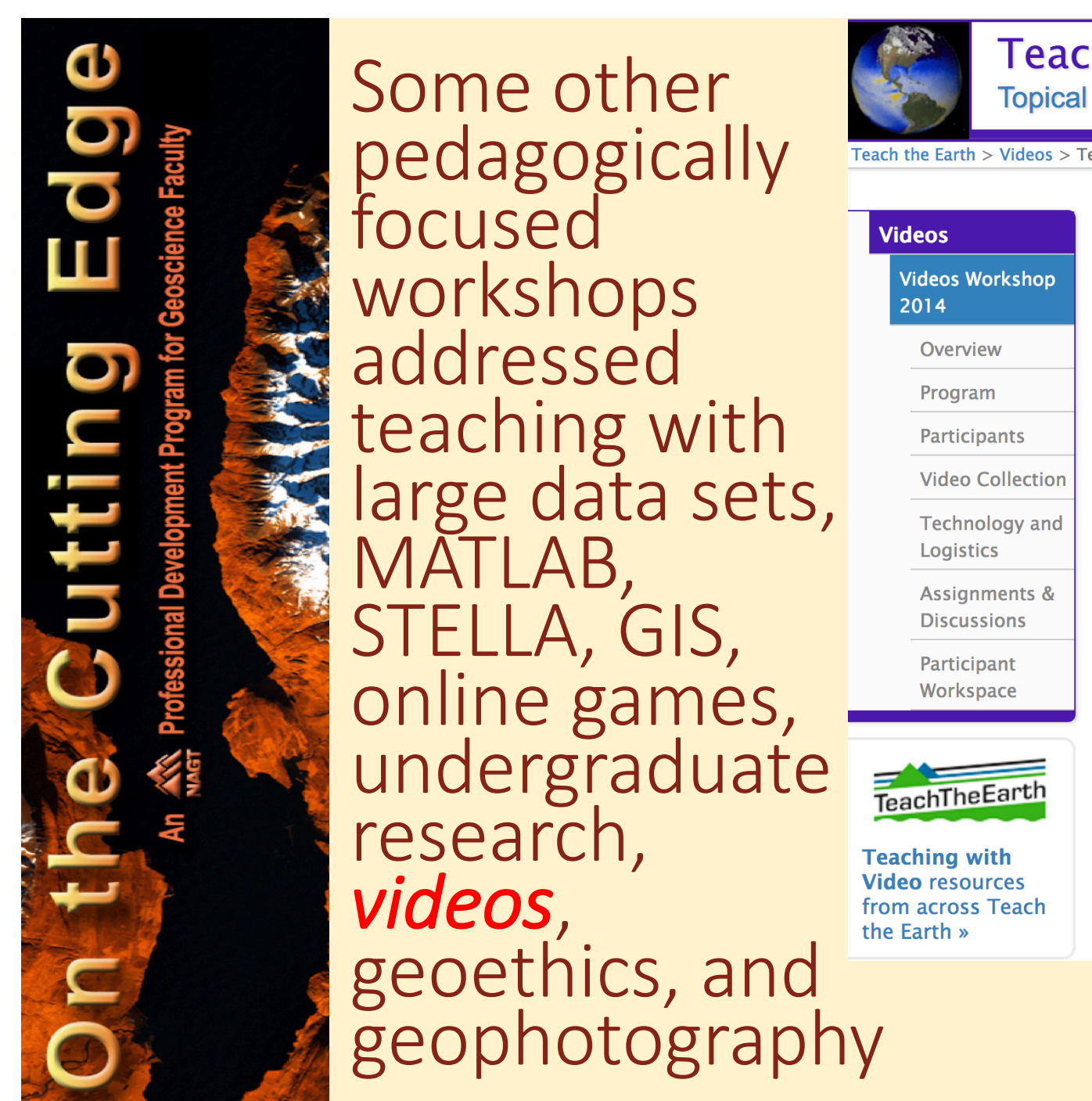

\section{Designing and Using Videos in Undergraduate Geoscience Education}

Feb 7, March 7, April 4, May 2 - 2014 Virtual Workshop

Video-based educational resources are well suited to explaining the dynamic nature of geosciences,

specifically processes that challenge students to think both temporally and spatially. Sample topics that can be better visualized through video include coastal erosion, the development of disconformities, the retreat of a

glacier, and the formation of a dune. In addition, online educational resources and the shift toward digital courseware available through free online academies are testaments to the increasing integration of instructional videos into college educational resources. In this workshop, through a series of four monthly sessions, we will explore the best practices for designing and using videos, review the existing technology (hardware and software), share resources, develop new ones, and discuss the challenges and opportunities. We are especially interested in building a community to develop and share resources and research on using short, self-produced videos to strengthen geoscience teaching and learning.

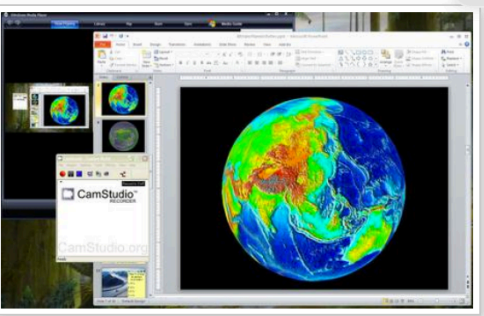
$<$ 


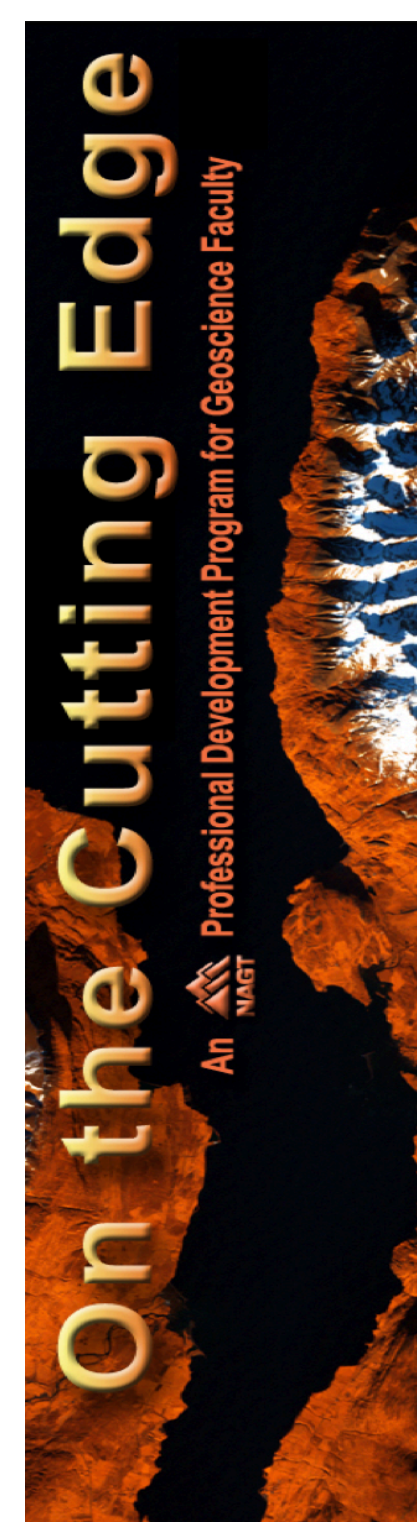

Some other pedagogically focused workshops addressed teaching with large data sets, MATLAB, STELLA, GIS, online games, undergraduate research, videos, geoethics, and

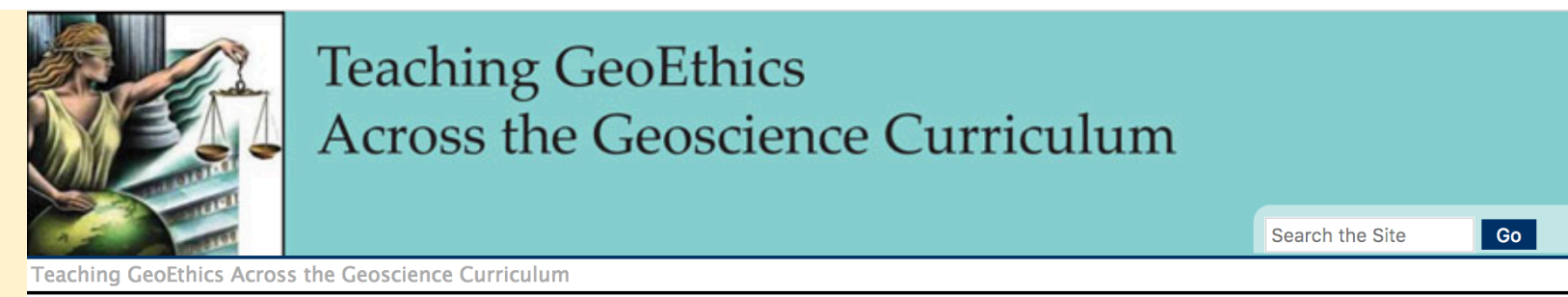

GeoEthics

What Is GeoEthics?

Why Teach GeoEthics

How to Teach GeoEthics

GeoEthics and Self

GeoEthics and Profession

GeoEthics and Society

CeoEthics and Earth

Selected GeoEthics

Resources

Case Studies Collection

\section{Teaching GeoEthics Across the Geoscience} Curriculum

David Mogk, Department of Earth Sciences, Montana State University and Monica Bruckner, SERC, Carleton College

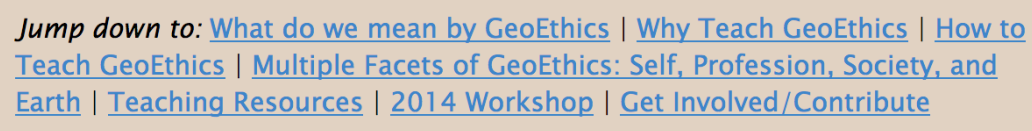

Jump down to: What do we mean by GeoEthics I Why Teach GeoEthics I How to Teach GeoEthics I Multiple Facets of GeoEthics: Self, Profession, Society, and

Earth | Teaching Resources | 2014 Workshop | Get Involved/Contribute

Ethics Education is an increasingly important component of the pre-professional training of (geo)scientists. Funding agencies (NSF, NIH) require training of graduate students in the responsible conduct of research, employers are increasingly expecting their workers to have basic training in ethics, and the public demands the highest standards of ethical conduct by scientists. Yet, few faculty have the requisite training to effectively teach about ethics in their classes, or even informally in mentoring students working in their labs.

This module has been developed to meet the need of introducing ethics education into the geoscience curriculum:

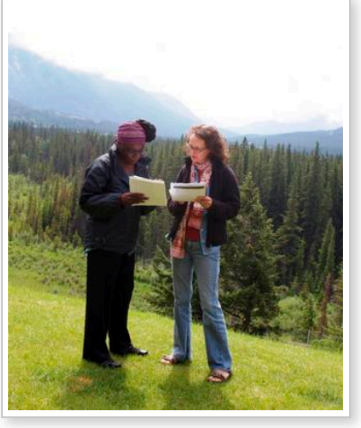
geophotography 


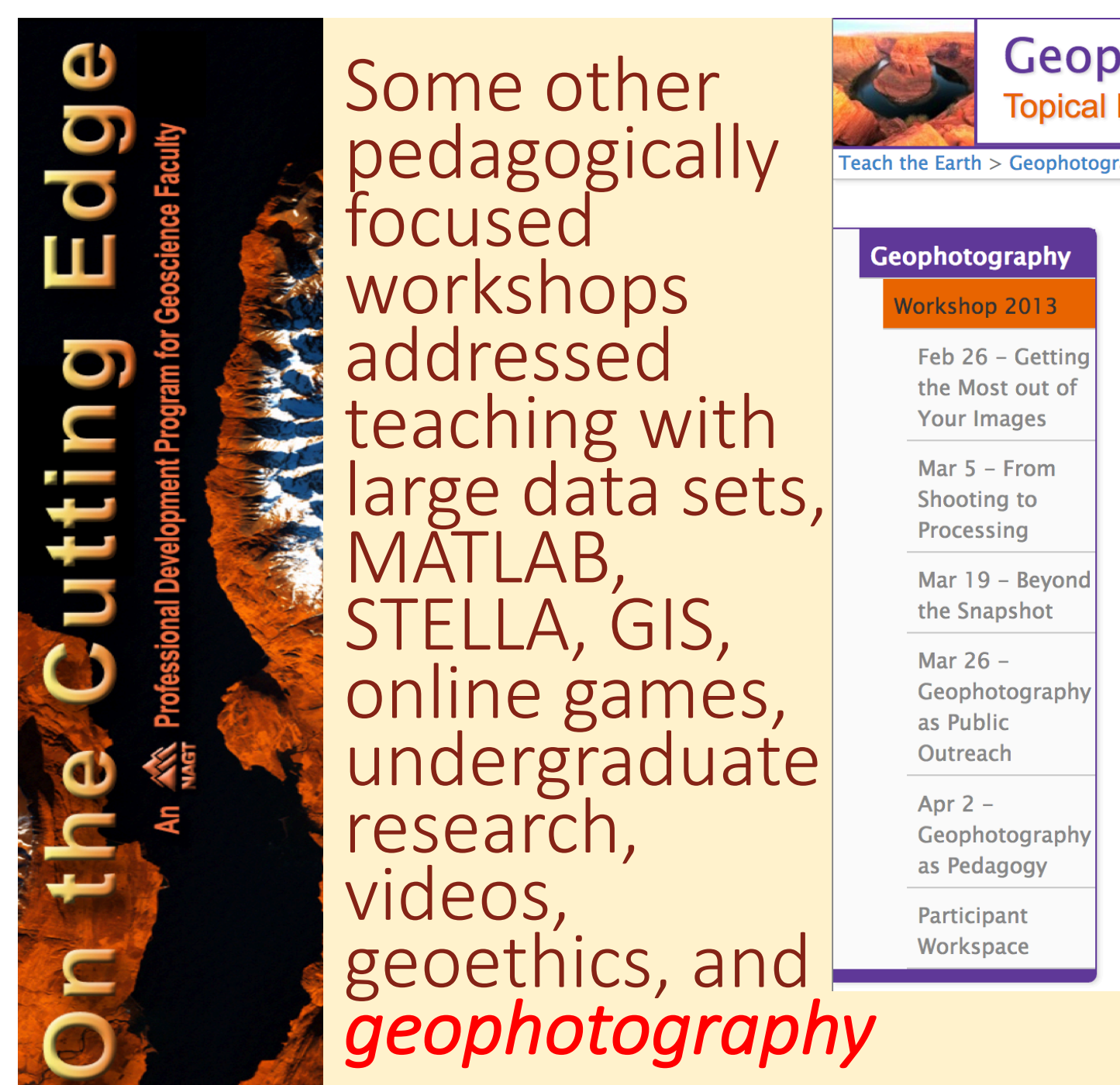

Geophotography

some other pedagogically tocused workshops addressed teaching with arge data sets, MATLAB STELLA, GIS, online games, undergraduate research, videos, geoethics, and

Geophotography

Feb 26 - Getting the Most out of Images

Mar 5 - From Shooting to Mar 19 - Beyond

Geophotography as Public

Geophotography as Pedagogy geophotography

\section{Geophotography} Webinar Series

\section{This event has already taken place}

The geosciences rely heavily on photographic images as one of the most important means by which information is recorded and shared.

Geophotography encompasses a number of genres: landscape and outcrop photography, mineral specimen photography, paleontological photography, repeat photography, time-lapse photography, photomicroscopy, and much more. However, rarely is any training afforded

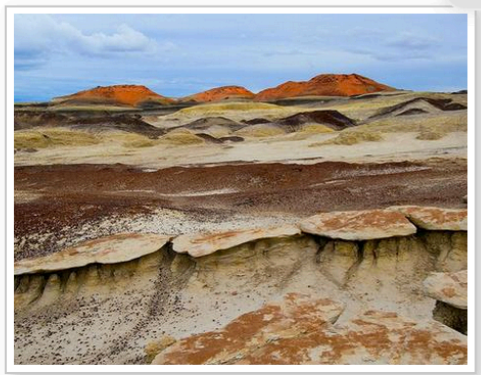
or forethought given to the photography of geologic features and processes. This workshop was convened to help geoscientists improve their photographic skills to enhance the creation and use of geo-imagery in research and instructional practices. 


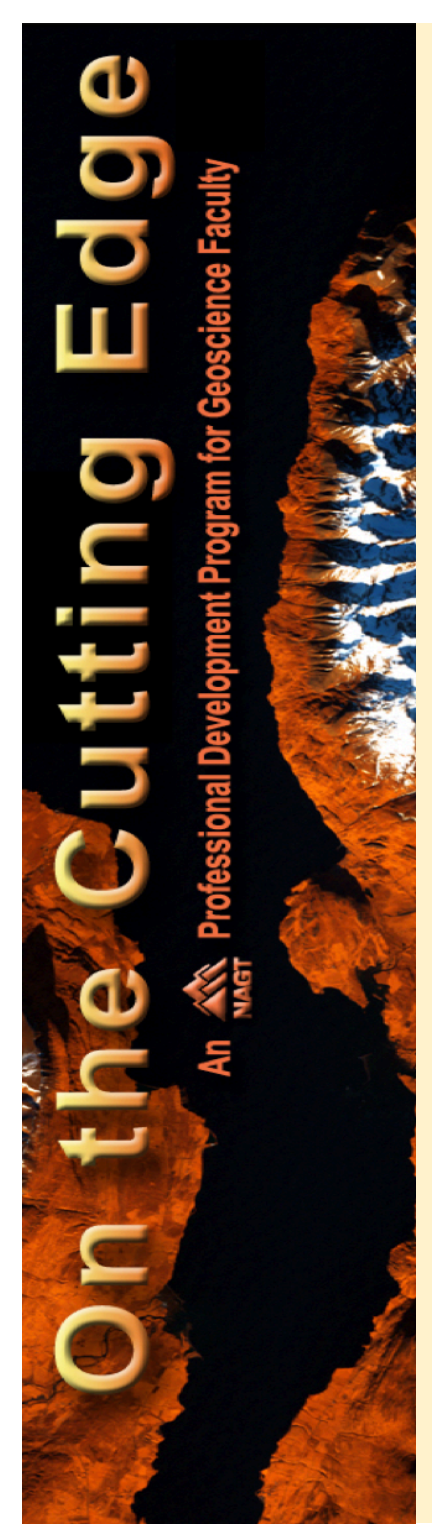

Understanding the Deep Earth

Content workshops involved topics such as the Deep Earth, the Early

Earth, Biocomplexity, Geologic Time, Geology and Human Health, Visualizing Seismic Waves, and Seismic Tomography

Online Workshop

each the Earth > Deep Earth > Understanding the Deep Earth

Deep Earth Understanding the Deep Earth: Slabs, Drips, Workshop 2010 Overview

Program

Participant

Workspace

Discussions

Activities in

Progress

Hot Topics

Participants

Participant

Checklist

Activity Design Plumes and More

February 17-19, 24-26, 2010

Virtual Workshop

This workshop has already taken place. See the Workshop Program for links to presentations, discussions, and other material from the workshop.

Be a part of this virtual workshop that will explore some of the latest science relating to the deep earth and how to use it in the undergraduate classroom. In this context, "deep earth" is considered to include the deep crust as well as the core and mantle. The workshop will consist of a blend of synchronous presentations, online discussions, work time and collaborative efforts.

\section{TeachTheEarth}

Deep Earth

resources from

across Teach the Earth »

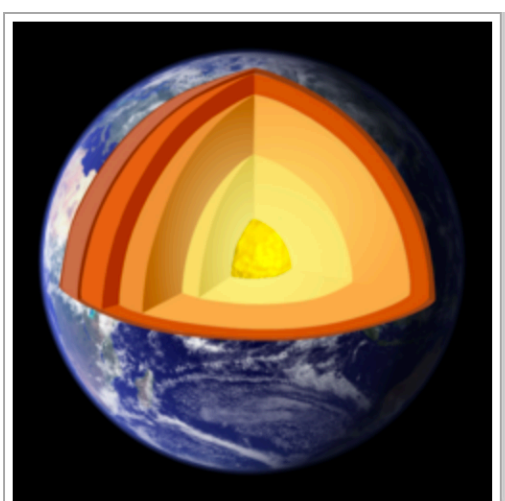

Image courtesy of Wikimedia Commons Participants will learn more about data, tools, and research

related to the deep earth and then spend time developing and reviewing teaching activities for use in the classroom. 


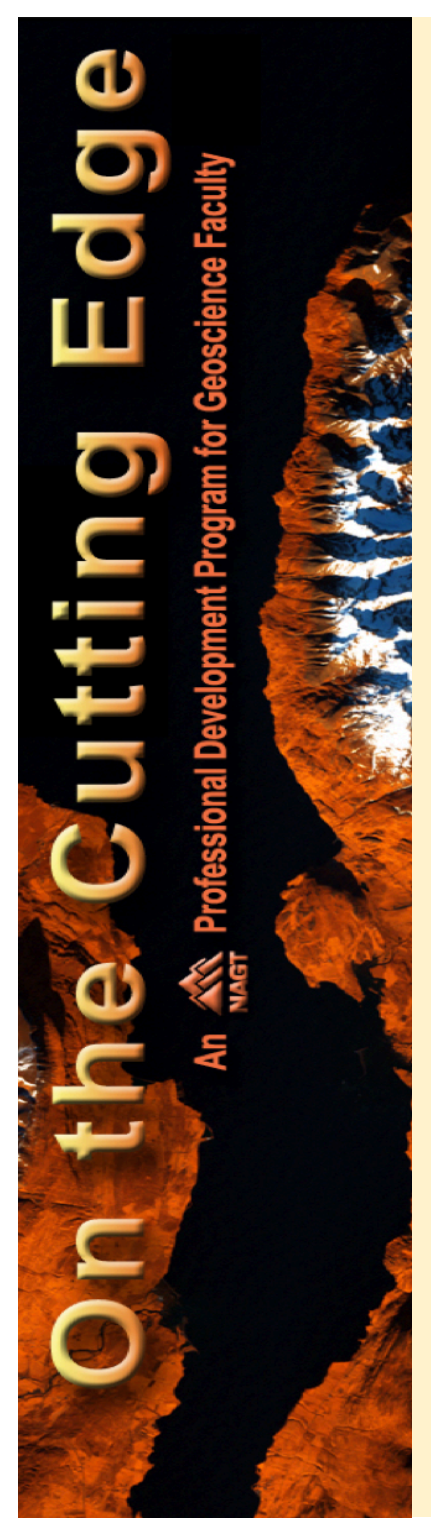

Content workshops involved topics such as the Deep Earth, the Early

Earth, Biocomplexity, Geologic Time, Geology and Human Health, Visualizing Seismic Waves, and Seismic Tomography

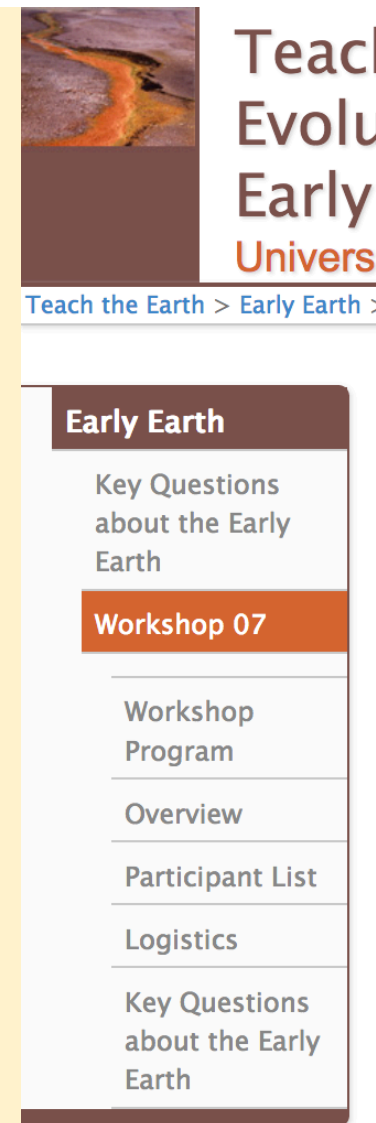

\section{TeachTheEarth}

Early Earth resources from across Teach the Earth »

\section{Workshop on Teaching about the} Early Earth: Evolution of Tectonics, Life, and the Early Atmosphere

April 12-14, 2007, University of Massachusetts, Amherst, MA

Many a geology professor has told their students "the present is the key to the past," but what about the deep past? What do we know about the formation of the continents, oceans and atmosphere and the emergence of life?

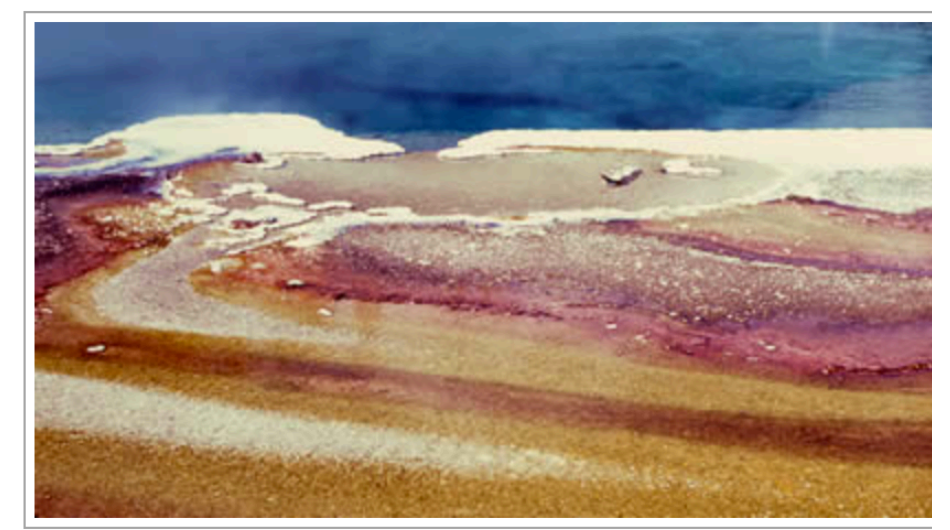
How are these early developments related to modern processes? Recent research aboul the early earth has not only shed light on some of the formative processes at work but has also provided new ideas and hypotheses to use in undergraduate teaching. 


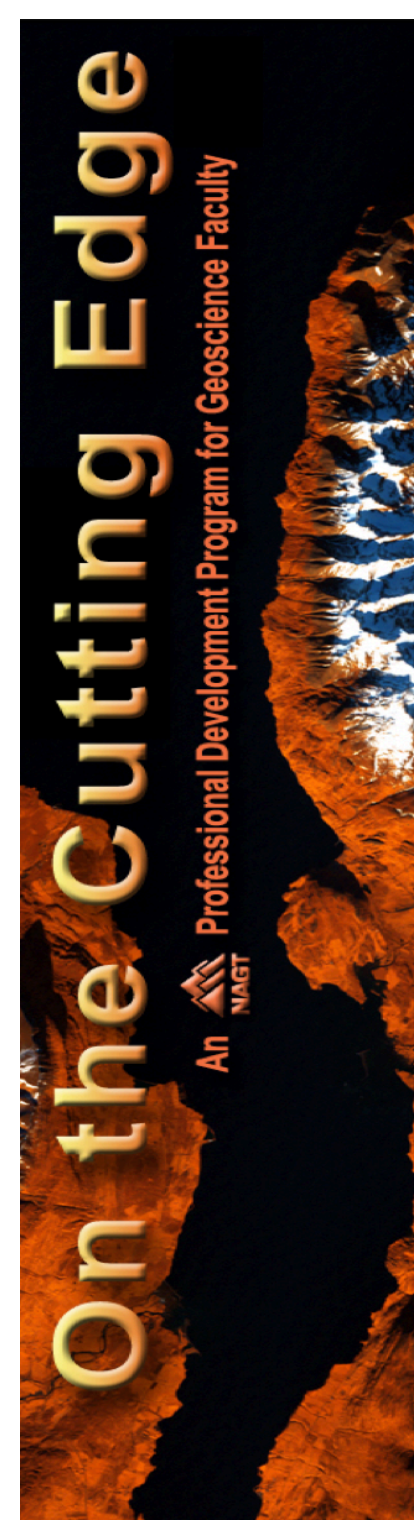

Content workshops involved topics such as the Deep Earth, the Early

Earth, Biocomplexity, Geologic Time, Geology and Human Health, Visualizing Seismic Waves, and Seismic Tomography
Biocomplexity

Workshop 03

Workshop

Program

Participants

Icebreaker

Posters

Share Fair

\section{TeachTheEarth}

Biocomplexity

resources from

across Teach the Earth $\gg$

\section{Teaching Biocomplexity in the Geosciences} Workshop

April 2 - 5, 2003

Chico Hot Springs Resort - Pray, Montana

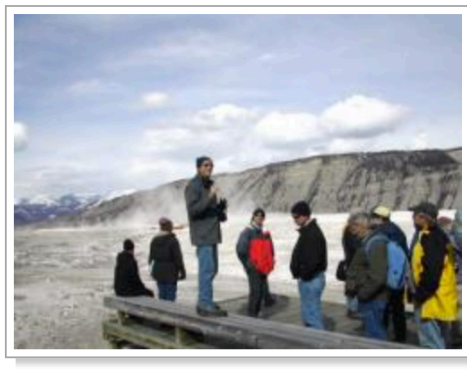

This workshop was intended to provide the first steps towards addressin the questions of "where" and "how" we are teaching biocomplexity in the geoscience undergraduate curriculum. From instructional modules in introductory physical geology/geography or Earth system science courses to upper division courses or seminars, there is an increasing interest in integrating biocomplexity in the geoscience curriculum.

The workshop was held at Chico Hot Springs Resort (just north of

Yellowstone National Park). Workshop activities included small group discussions and planning/writing sessions to determine the next steps towards the creation of biocomplexity instructional materials for the geosciences. Workshop activities included opportunities to demonstrate and share current educational activities about biocomplexity and a one-day field trip to Yellowstone National Park to explore biocomplexity at Mammoth Hot Springs and the northern range ecosystem.

Applications were invited from individuals who have active interests in teaching and research about biocomplexity from all institutions of higher learning (e.g. 2YC, liberal arts colleges, comprehensive and research universities), and from all

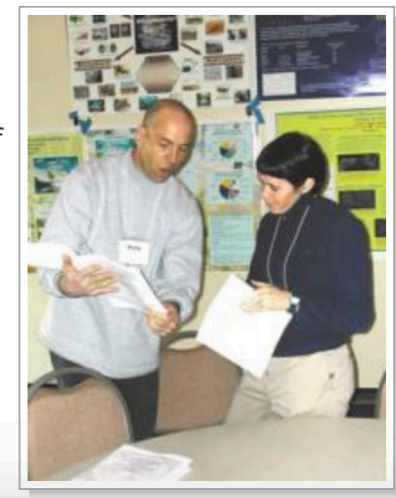




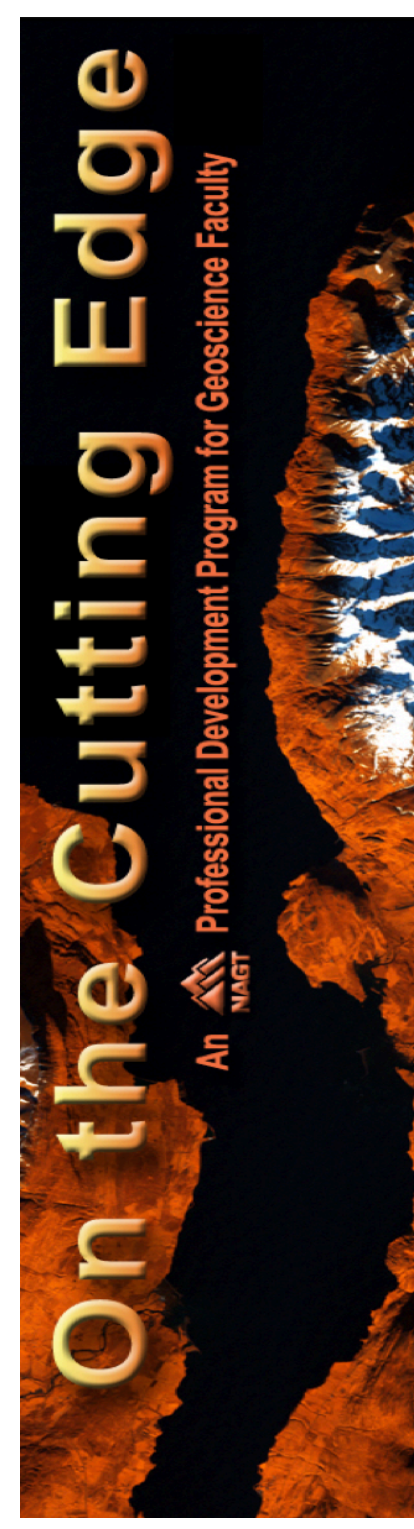

Content workshops Rates and Time involved topics worksop 2012 such as the Overview Deep Earth, the Early Earth, Biocomplexity, Geologic Time, Geology and Human Health, Visualizing Seismic Waves, and Seismic Tomography

Program

Participants and

their

Contributions

Logistics

Participant Checklist

Temporal Learning

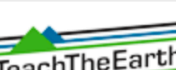

TeachTheEarth

Rates and Time resources from across Teach the
Earth "

\section{Workshop: Teaching} About Time

\section{February 26-28, 2012}

Arizona State University

Note: This workshop has already taken place. See the workshop program for links to presentations, discussions, and other material from the workshop, and the workshop synthesis for a summary of key ideas.

On the Trail of Time at the Grand Canyon. Photo by Steve Semken.
Time and temporal concepts are critically important in a wide range of disciplines, from geoscience and other natural sciences to history and archeology. Students struggle with rates and scales of processes that are beyond their personal experiences, with the complex interactions of slow processes over long time scales, and with the enormous numbers involved in Deep Time. A sophisticated understanding of these temporal concepts is an essential foundatio for unraveling the complex histories of the Universe, solar system, and Earth; of species; and of civilizations. It is also key for contextualizing the natural and anthropogenic changes occurring on our planet today.

Join us for a workshop that will bring together faculty teaching about time with researchers studying temporal learning to

1. Understand current best practice in teaching about time,

2. Bring forward ideas from education and cognitive psychology that can inform improved practice, and 3. Work together in ways that support improved teaching about time. 


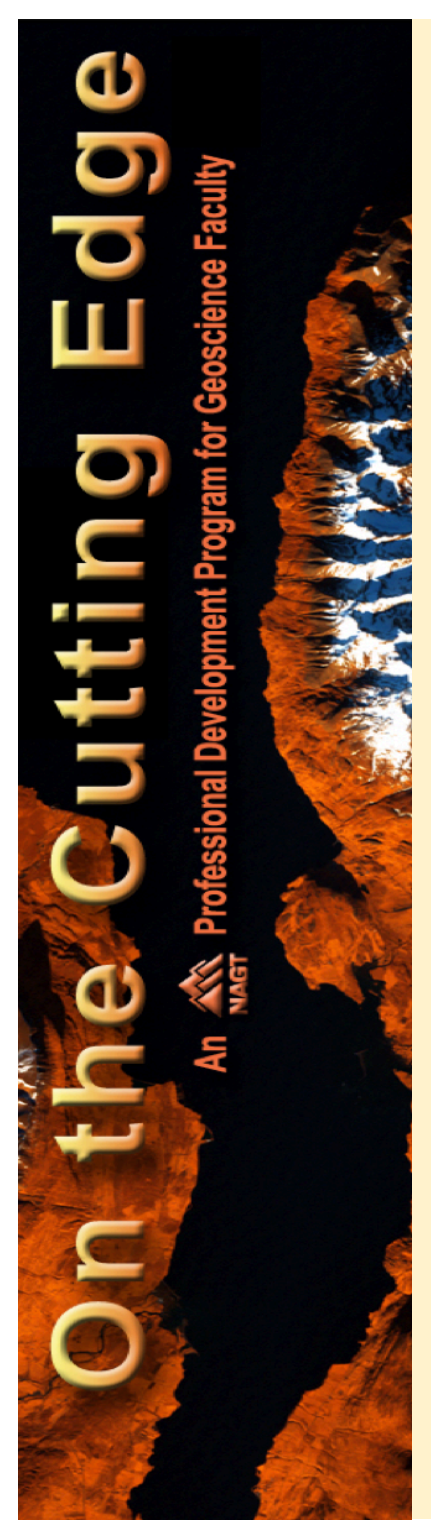

Content workshops involved topics such as the Deep Earth, the Early

Earth, Biocomplexity, Geologic Time, Geology and Human Health, Visualizing Seismic Waves, and Seismic Tomography

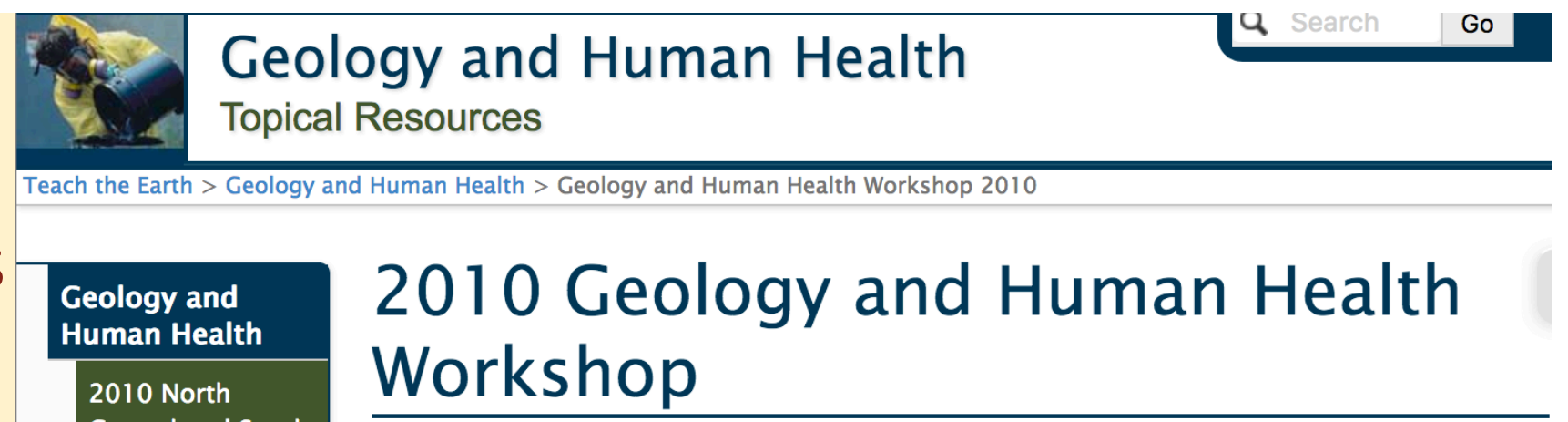

Central and South

Central GSA

Workshop

Overview

Program

Recommended

Readings

Workshop 04

\section{TeachTheEarth}

Geology and Health resources from across Teach the Earth »

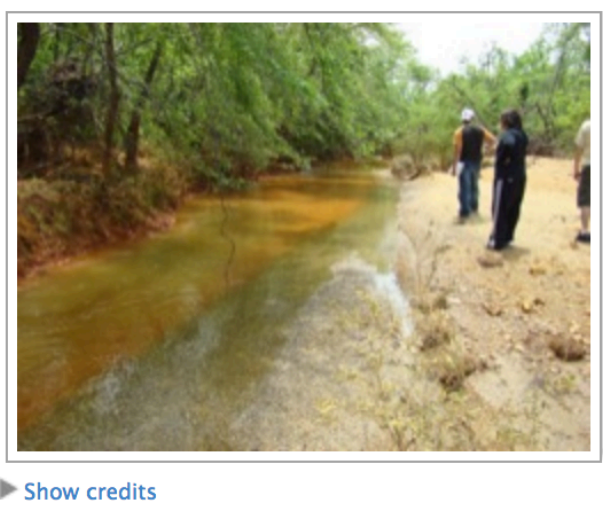

\section{Workshop Description}

This workshop on Geology and Human Health is a follow-up to the original 2004 workshop. We will focus on the importance of geological materials and processes in human health. Historical evolution of the new subspecialty, referred to as Medical Geology (in Europe and elsewhere) and Geology and Human Health (U.S.) will be reviewed and case histories linking geology to occurrence of disease and its 


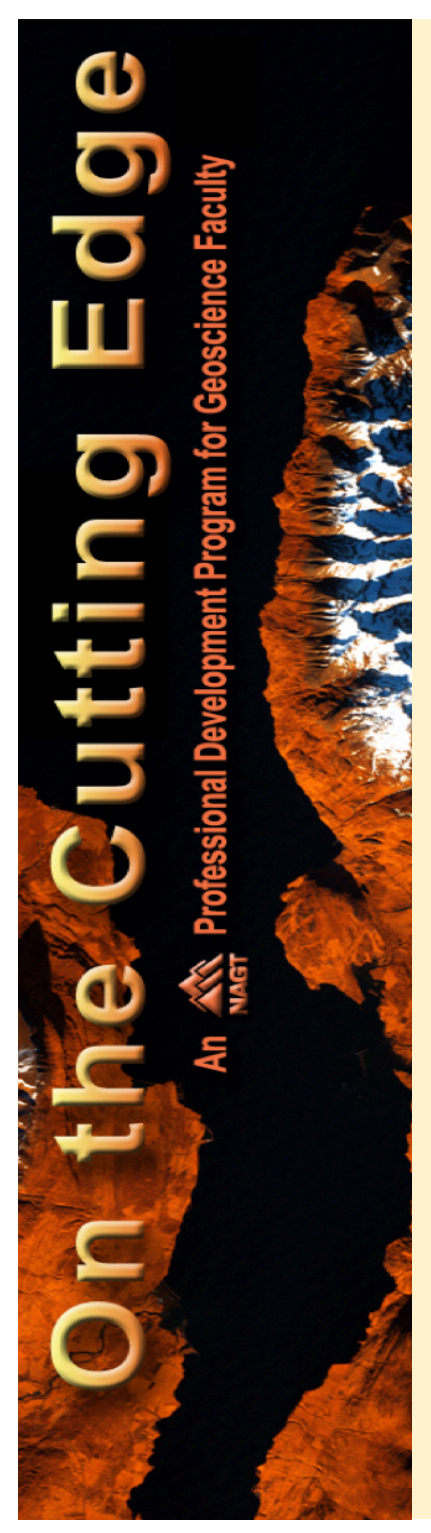

Content workshops involved topics such as the Deep Earth, the Early

Earth, Biocomplexity, Geologic Time, Geology and Human Health, Visualizing Seismic Waves, and Seismic Tomography

\begin{tabular}{l} 
Teach \\
Geophysics \\
\hline Visualizing \\
Seismic Waves for \\
Teaching and \\
Research \\
\hline Overview \\
\hline Program \\
\hline Visualization \\
Collections \\
\hline Share an Activity \\
\hline Workshop \\
Participants \\
\hline Participant \\
Workspace \\
\hline Discussions \\
\hline Workshop \\
Upload \\
\hline End of \\
Workshop \\
Evaluation \\
Workshop 07 \\
\hline Interpreting and \\
Teaching with \\
Tomograms \\
\hline
\end{tabular}

\section{Visualizing Seismic Waves for} Teaching and Research

A hybrid online/face-to-face workshop running February through April, 2011 , with a follow-up meeting at the Fall, 2011 , AGU meeting

Registration for this workshop is closed.

Remarkable new advances in visualizing seismic waves now provide exciting opportunities for teaching and learning in the areas of geophysics dealing with earthquakes, earth structure, and seismic wave propagation. Following the Understanding Deep Earth workshop in 2010, participants recommended that new collections of visualizations were needed to help students (and colleagues in related geoscience disciplines) to understand the underlying principles of seismology, to visualize what earthquake waves look like as they propagate through Earth, and to be able to work with seismograms and the comprehensive seismological data that are now available via IRIS, EarthScope (more info), and SCEC. 


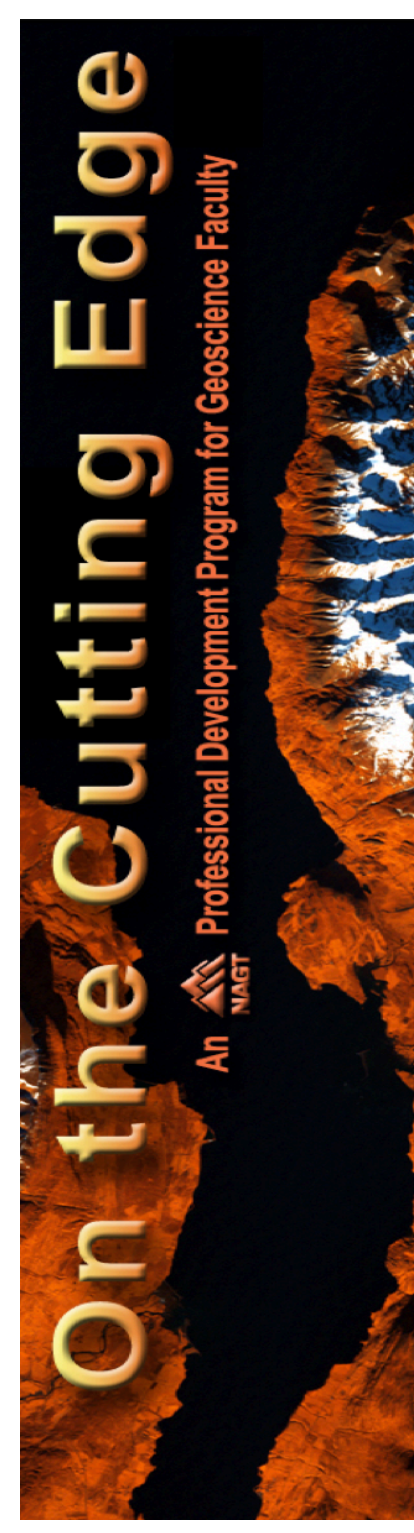

Content workshops involved topics such as the Deep Earth, the Early

Earth, Biocomplexity, Geologic Time, Geology and Human Health, Visualizing Seismic Waves, and Seismic Tomography
Teaching Geophysics in the 21 st Century

Topical Resources each the Earth > Geophysics > Interpreting and Teaching with Tomograms

Geophysics

Visualizing Seismic

Waves for

Teaching and

Research

Workshop 07

Interpreting and

Teaching with

Tomograms

Overview

Technical

Information

Program

Participants

Participant

Checklist

Submit a

Teaching

Activity

Submit a Course

Description
Seismic Tomography for Teaching and Research

An online virtual workshop; Six 2-hour virtual sessions in April $(3,10,17,24)$ and May $(22,29)$, 2013

Registration for this workshop is Closed.

Seismic Tomography plays a vital role in conveying information about the structure, composition, and state of Earth's interior. The images produced by seismic tomography, however, are difficult to construct

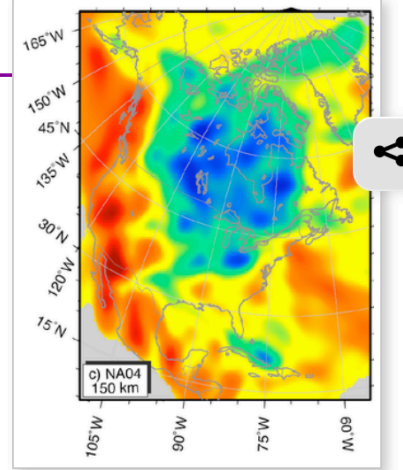
and complex to interpret. This workshop will follow upon two previous

solid-Earth geophysics workshops (the Understanding Deep Earth workshop in 2010, and the Visualizing Seismic Waves workshop in 2011) to help faculty member bring geophysics into their classroom and labs; in this case, in the area of the construction and interpretation of seismic tomographic images, or "tomograms."

During April-May, 2013, a virtual workshop will be held in six 2-hour sessions (Wednesday, 12-2 pm Central Time) to help the geoscience community identify, develop, and organize a comprehensive collection of activities that will facilitate learning about seismic tomographic images, the information they convey, and how they are used for a wide variety of geoscience applications. The first four of 


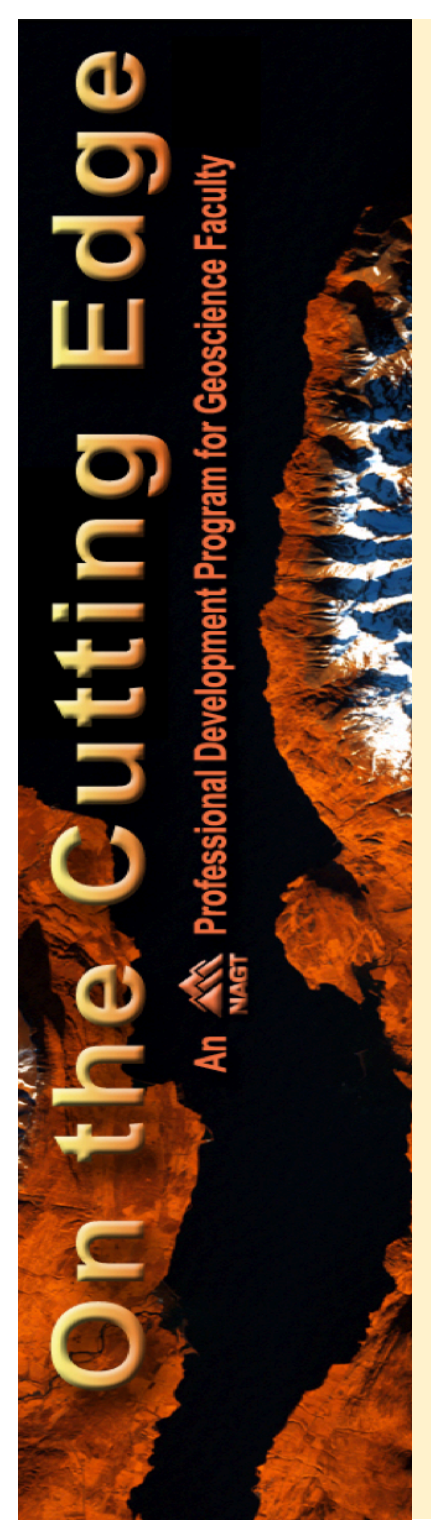

Workshop outputs include presentations, classroom activities, publications, course syllabi, reference lists, tutorials, etc., and are available on the Teach the Earth website.

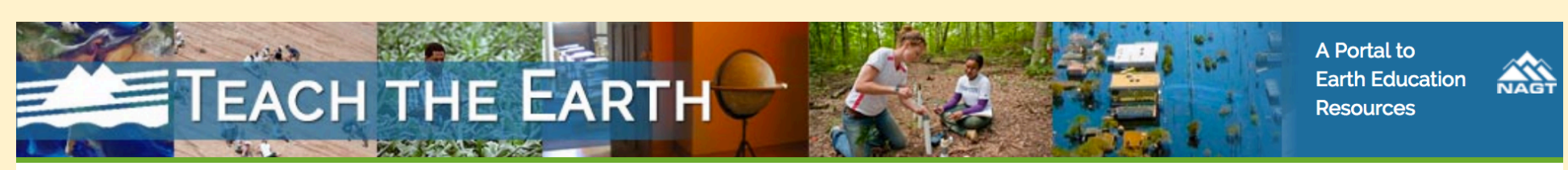

About

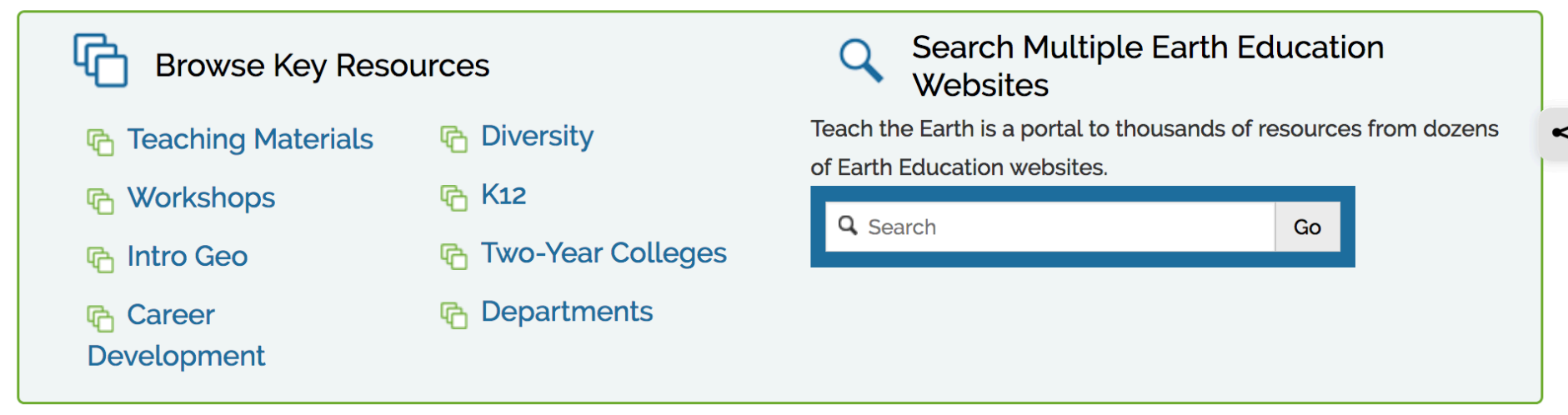

\section{$\equiv$ Explore Themes}

Course Topics

Atmospheric Science

Biogeoscience

Ecology
Incorporating Societal Issues Climate Change

Complex Systems

Energy
Teaching Topics Biocomplexity Deep Earth Early Earth
H+H Wewhs \& Events

Enhancing your Teaching

Affective Domain

Assessment

Course Design

Data, Simulations, Models
NAGT Announces New Editor of the Journal of Geoscience Education (JGE)

The National Association of

Geoscience Teachers (NAGT) is pleased to announce that Dr. Anne 


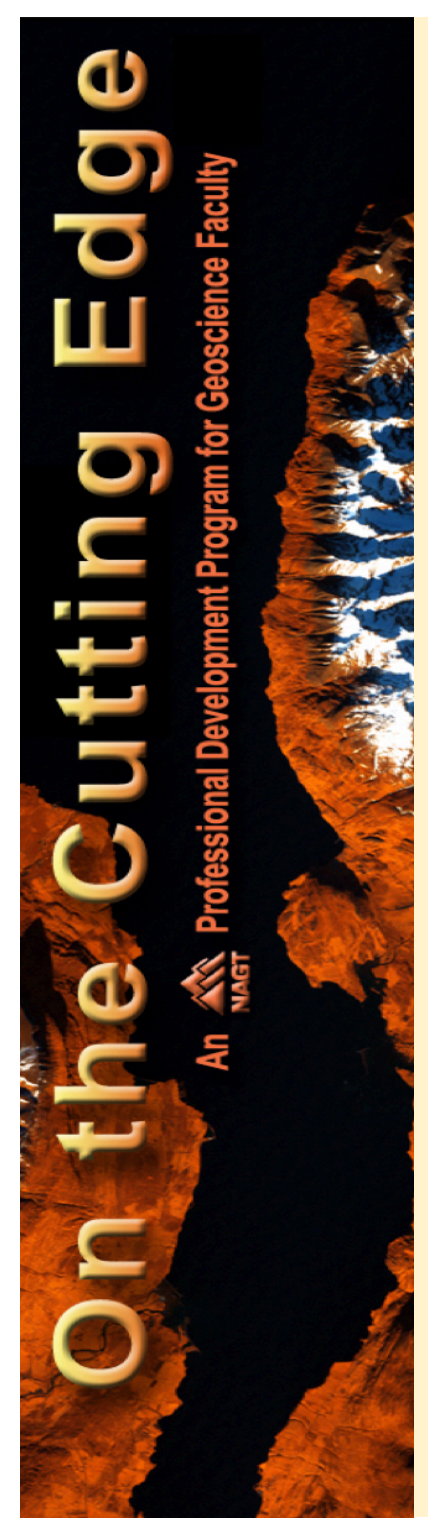

\section{New teaching activities can still be added by community members, and discussion lists remain available to support interaction among interested parties.}

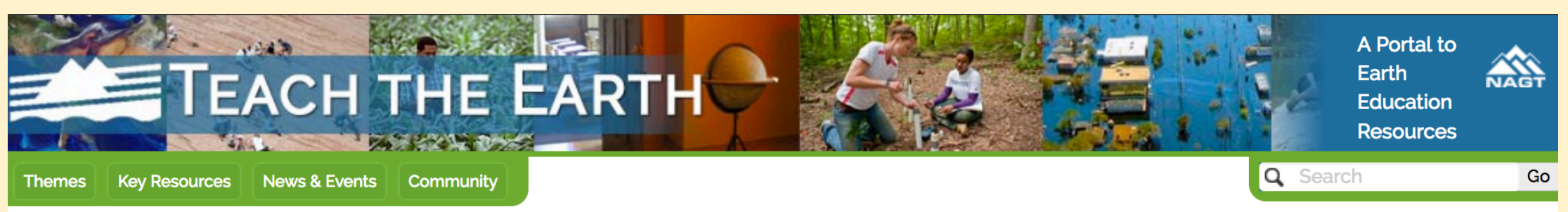

Teach the Earth

Search the Portal

Earth Education

Project Sites

Community

Join Teach the

Earth

Contribute

Activity

News

Workshops,

Webinars and

Events

About this Portal

\section{Contribute an Activity to Teach the Earth}

Have you developed your own activity that has worked well in your own classroom or in the field? We are always looking for activities to share with our community and beyond. If you have an Earth education teaching activity that you would like to share with other educators, use this form to tell us about it. The information you provide here will be used to create a web page describing your activity. Activities go through review (opens in a new window) on an annual basis, and you will be recognized for passing the review process and contributing an exemplary activity.

Before you start, explore the collection. To see the best examples of the kinds of activities that have been contributed, explore the exemplary collection (opens in a new window) Search the entire collection (opens in a new window) to see if an activity like yours already exists in our collections. This is especially important if you are contributing an activity that is based on another person's activity or that others may use in their course. If your activity is very similar to one that is already in our collections, please email SERC for options on how to proceed. 


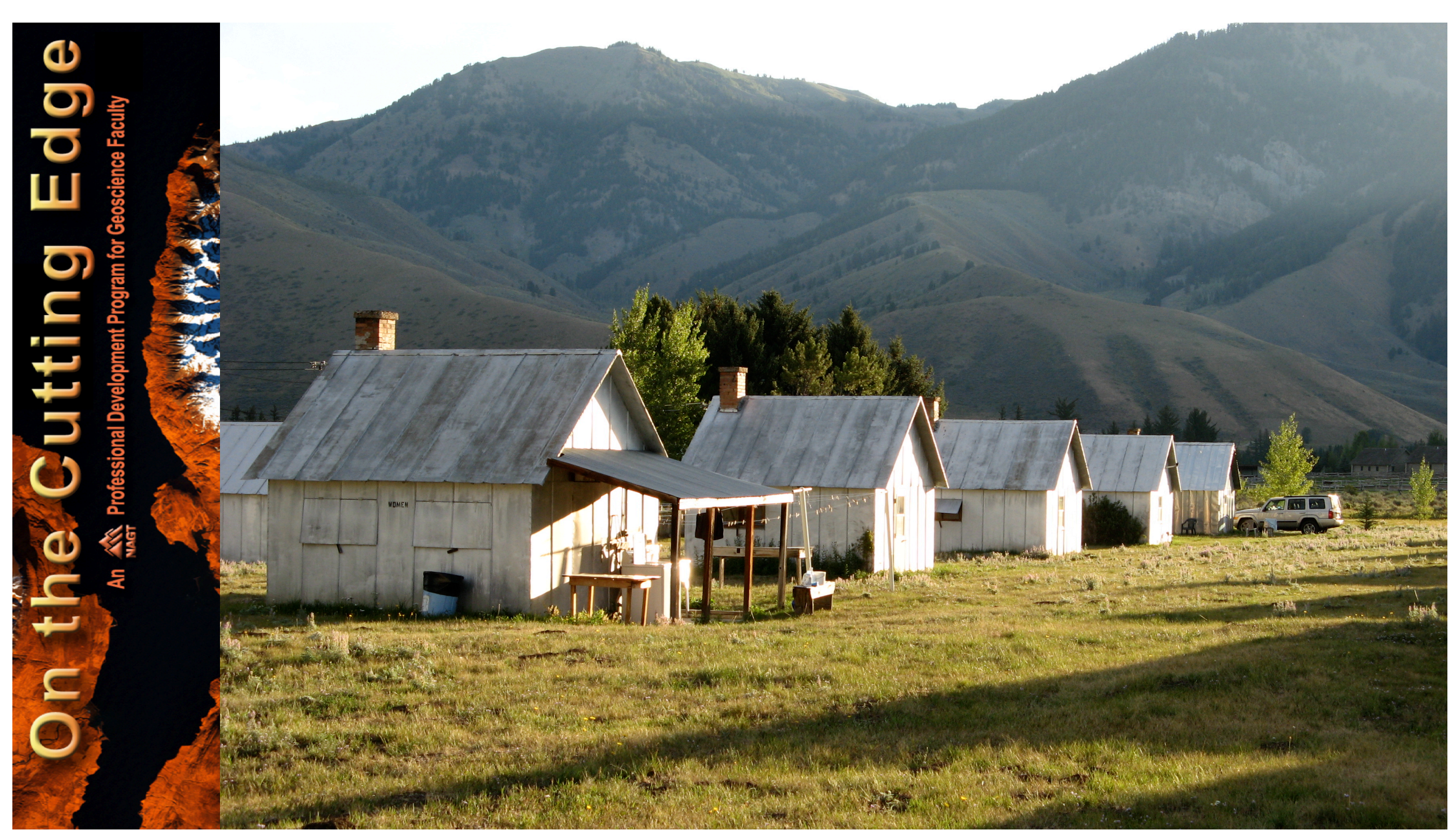




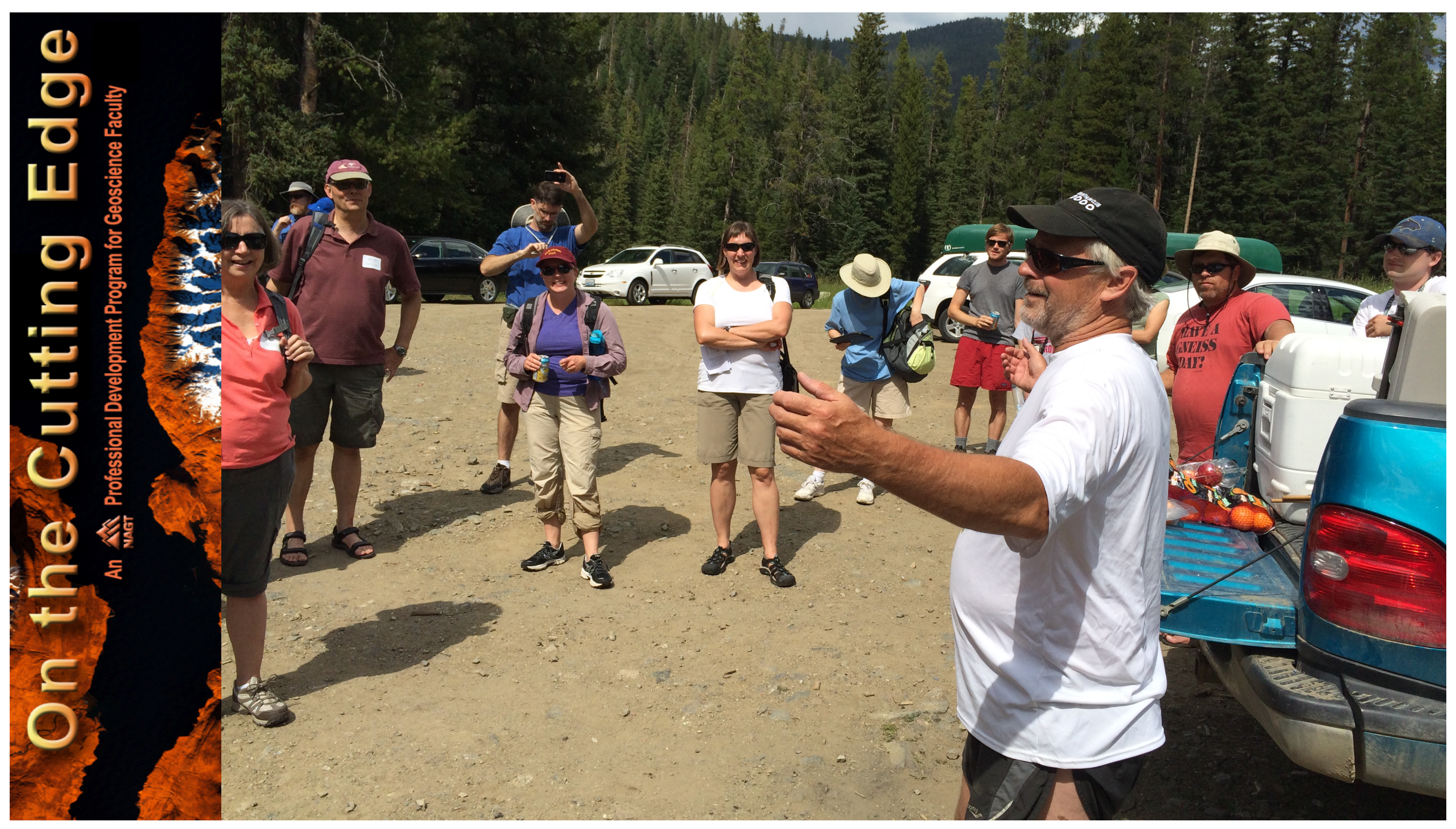




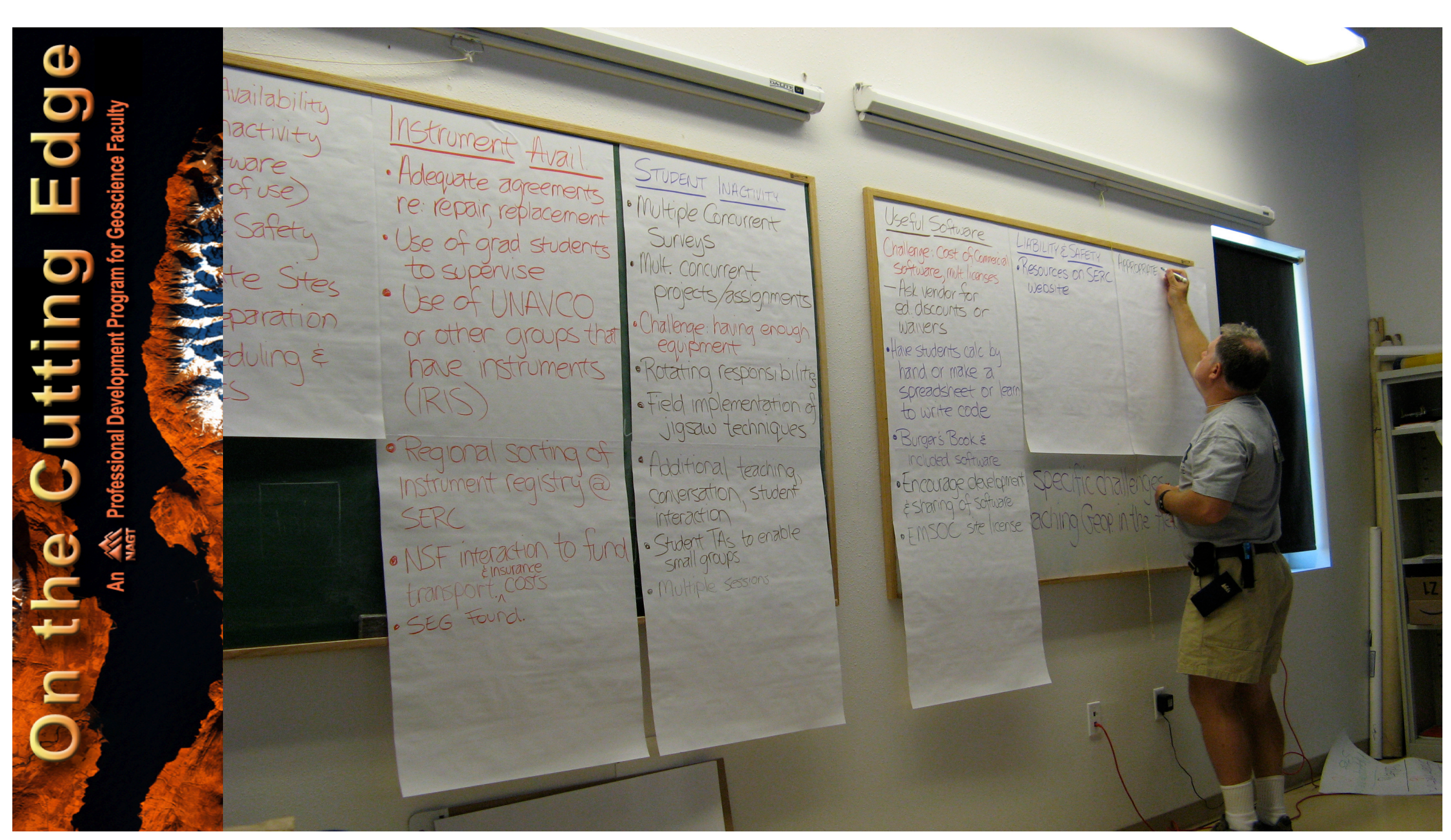




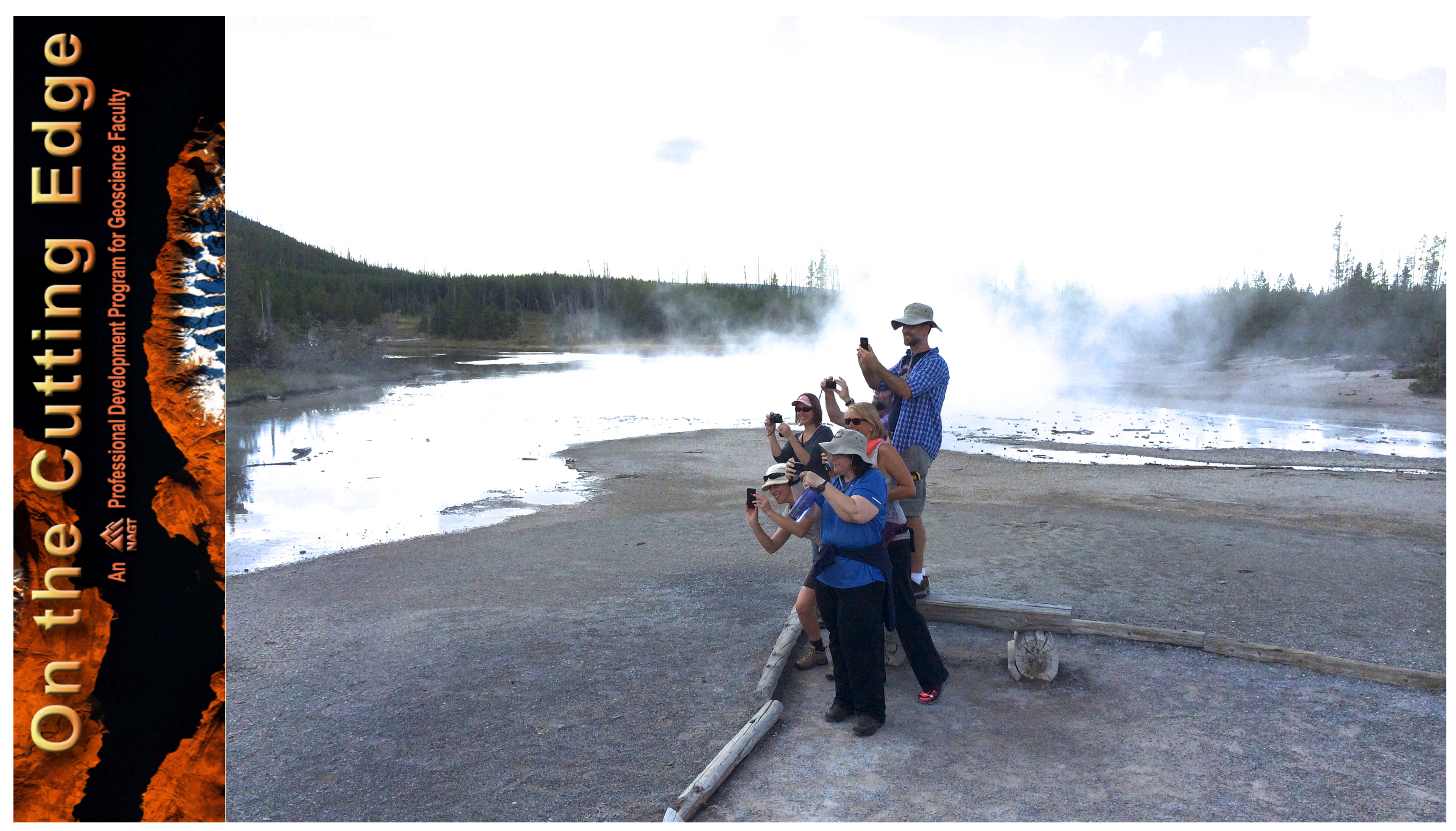




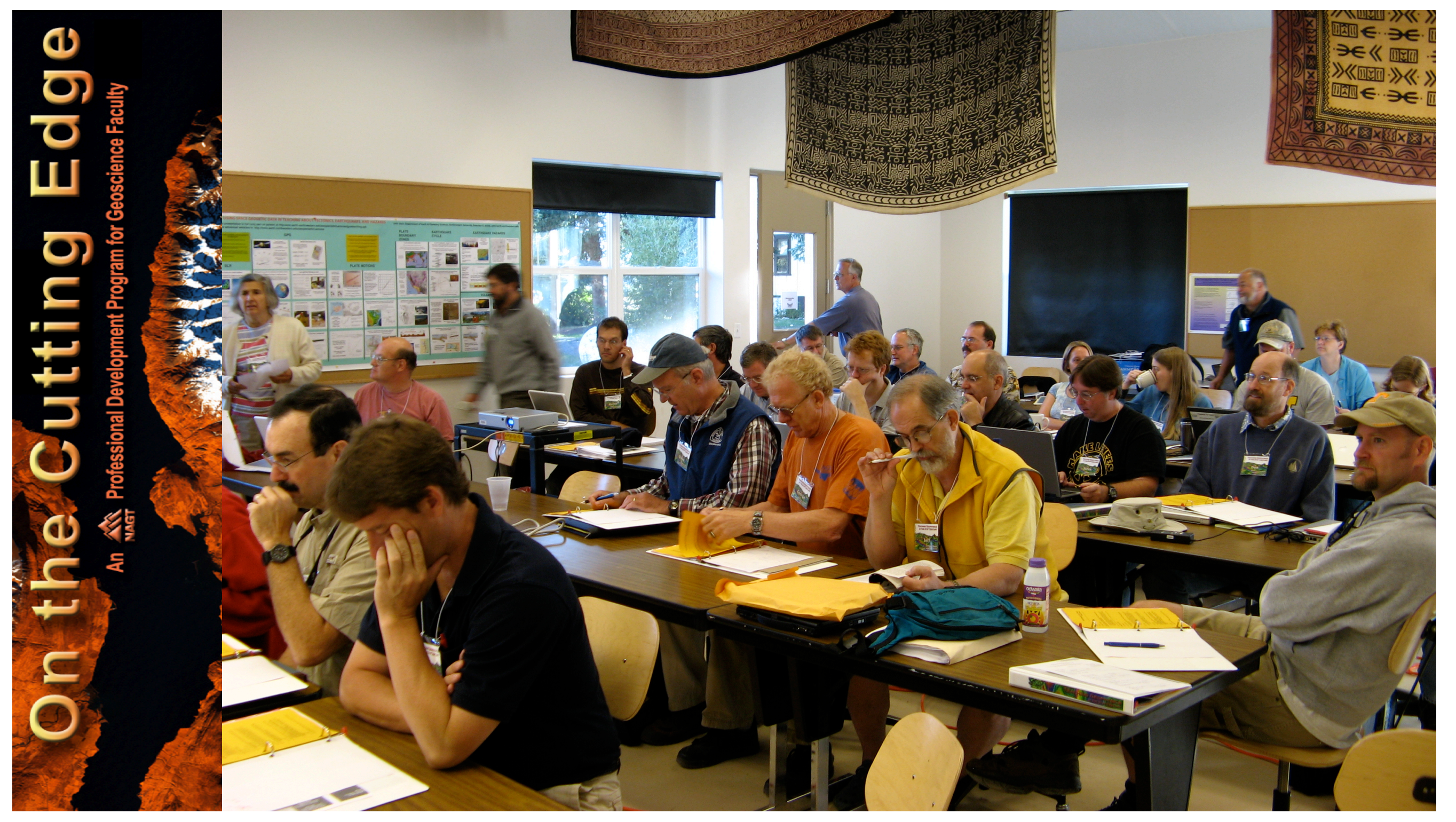

